\title{
General Management Plan
}

August 1995

\section{GRAND CANYON NATIONAL PARK・ARIZONA}

United States Department of the Interior $\bullet$ National Park Service $\bullet$ Denver Service Center 


\section{Recommended:}

Robert L. Arnberger

Superintendent, Grand Canyon National Park

August 21, 1995

\section{Approved:}

Stanley T. Albright

Field Director, Pacific West Area

August 21, 1995 
Grand Canyon National Park today encompasses approximately 1,218,375 acres of public land on the southern end of the Colorado Plateau. It is a globally significant natural resource containing scenic vistas known throughout the world. In recognition of its significant values, Grand Canyon National Park was designated as a world heritage site on 0ctober 26, 1979.

A 277-mile stretch of the Colorado River runs through the park, and thousands of miles of tributary side-canyons are included within its boundaries. The exposed geologic strata - layer upon layer from the basement Vishnu schist to the capping Kaibab limestone - rise over a mile above the river, representing one of the most complete records of geological history that can be seen anywhere in the world.

The park contains several major ecosystems from the mixed Mohave desertscrub of the lower canyon to the coniferous forests of the North Rim. Many species of plants and animals make up these diverse ecosystems. While many wild creatures live out their entire lives within the protected park area, migratory species also benefit from the temporary sanctuary that the park affords.

Over four million recreational visits are recorded in the park each year, primarily on the South Rim. Recreational pursuits include river running, fishing, hiking, photography, nature study, and sightseeing. But a vacation to the Grand Canyon can become more than a recreational or scenic venture. The canyon's grandeur and the awesome physical forces that are continuing to shape it can transform the experience of a perceptive visitor from a casual sightseeing trip to one that helps form or influence personal views of nature and individual responsibilities to conserve it.

A person's first view of the Grand Canyon often evokes awe and an overwhelming sense of wonder. As one attempts to comprehend the grandeur and scenery rolling off to the far horizons, the tremendous size and depth of the canyon begin to make a second impression, intensifying the awe and deepening the wonder. This place is truly special. From a scenic perspective alone it is unique on the planet, but there are other attributes of the Grand Canyon that cannot be experienced or clearly understood from an overlook on the rim.

Almost the entire park is wild in character, and it is this pristine natural setting that imparts another dimension to the experience of visiting the canyon. Thousands of acres of untrammeled country allow a person to hike for days in solitude and, from time to time, to experience natural quiet. But visitors do not have to immerse themselves in wilderness to appreciate what it means to them and to the human spirit. Whether one is rafting down the river, hiking along the Tonto Trail, or enjoying panoramic views from the rim - it is during the quiet times, as the long shadows of evening fill the side canyons and the cool air descends in soft breezes from the rim, that one can look inward as much as outward and experience again that same awe and wonder, and understand that the essential wildness of the Grand Canyon is a precious gift that we must cherish and protect.

\section{WORLD HERITAGE SITE GRAND CANYON NATIONAL PARK • ARIZONA}




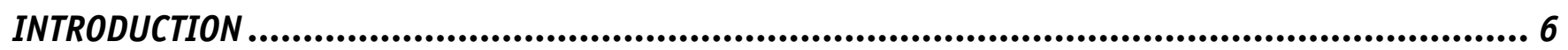

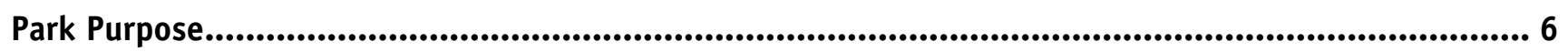

Park Significance .......................................................................................................................................... 7

Park Vision Statements..............................................................................................................10

Management Objectives ..............................................................................................................................12

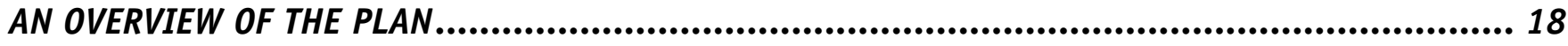

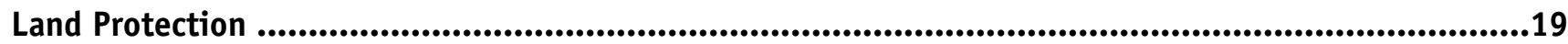

Natural Resource Management .................................................................................................................22

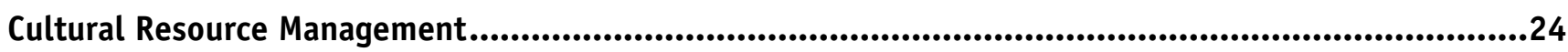

Themes For Interpretation ................................................................................................................26

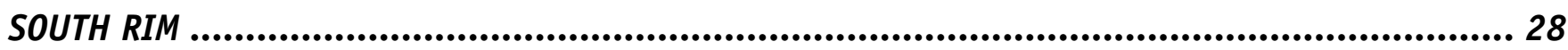

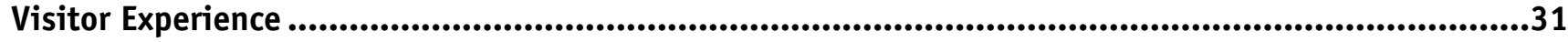

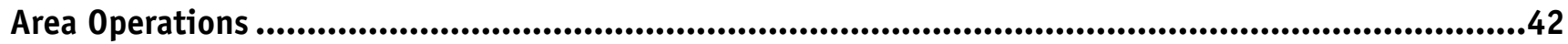

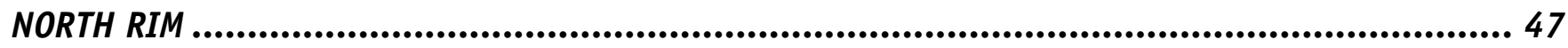

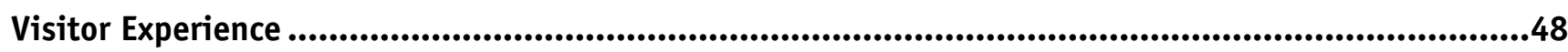

Area Operations ..........................................................................................................................

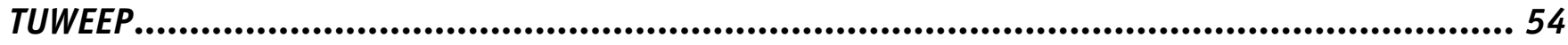

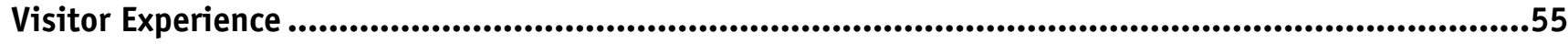

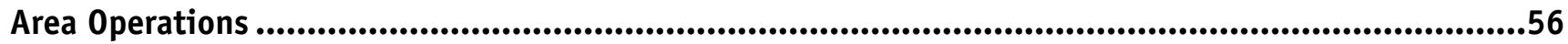

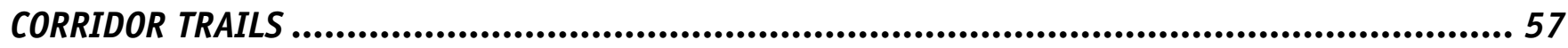

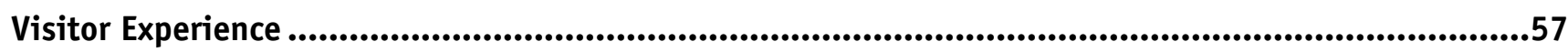

Area Operations ........................................................................................................................59

INTERRELATIONSHIP OF THIS PLAN WITH OTHER PLANS AND PROJECTS ................................ 60

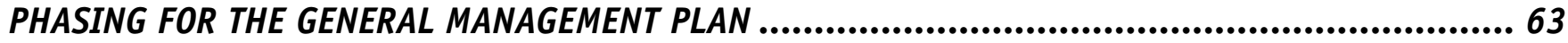

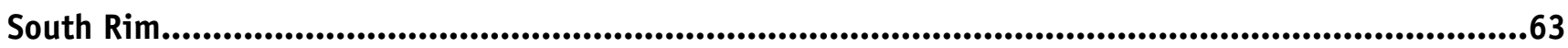

North Rim................................................................................................................................................71

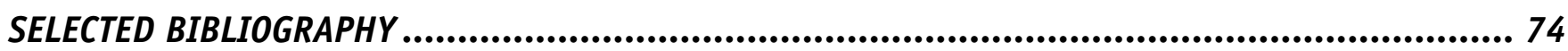

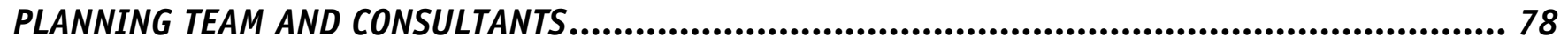




\section{Grand Canyon's Legislative History}

President Theodore Roosevelt, by presidential proclamation, reserved land in the Grand Canyon of Arizona as the Grand Canyon National Monument on January 11, 1908. President Roosevelt stated in the proclamation that the Grand Canyon of Arizona "is an object of unusual scientific interest, being the greatest eroded canyon in the United States, and it appears that the public interest would be promoted by reserving it as a National Monument" (Proclamation No. 794).

On February 26, 1919, Congress dedicated and set apart Grand Canyon National Park "as a public park for the benefit and enjoyment of the people" (Grand Canyon National Park Establishment Act, 40 Stat 1175). Over the years the park has been enlarged and its boundaries revised, most recently on January 3, 1975, when Congress recognized "that the entire Grand Canyon, from the mouth of the Paria River to the Grand Wash Cliffs, including tributary side canyons and surrounding plateaus, is a natural feature of national and international significance" (Grand Canyon National Park Enlargement Act, Public Law 93-620). In this act, Congress also recognized the need for "further protection and interpretation of the Grand Canyon in accordance with its true significance."

These legislative statements effectively provide the foundation upon which park management is based. Management seeks to protect the natural and cultural resources of the park, while providing for "the benefit and enjoyment of the people" through resource-based interpretive programs and appropriate public and concession facilities. 


\section{INTRODUCTION}

This General Management Plan for Grand Canyon National Park guides the management of resources, visitor use, and general development at the park over a 10- to 15-year period. The primary purpose of the plan is to provide a foundation from which to protect park resources while providing for meaningful visitor experiences. A secondary purpose is to encourage compatible activities on adjacent lands so as to minimize adverse effects on the park.

The direction for future park management is based on the laws establishing the park and the National Park Service (NPS), the purpose of the park, and its significant resources, as described below. These elements in turn are the foundation for park visions and management objectives. Collectively, these pieces provide the context and philosophical direction for the General Management Plan.

The most pressing issue in the park today is the impact created by the annual crush of nearly 5 million visitors and their private cars on the few developed areas along the canyon rims. The roads and facilities in developed areas of the park were never designed to handle this volume of use. The result has been the gradual degradation of the visitor experience and unacceptable impacts on the park's natural and cultural resources. No comprehensive management plan is in place that provides direction for the park when dealing with general visitor use or that guides appropriate development in the park.

While this plan provides overall direction for park management, the specific actions needed to implement the plan will be provided in subsequent plans. Where appropriate, the park's existing resource or issue-specific plans, and those being revised, are adopted by this plan (these plans are described beginning on page 60). Needed parkwide management plans (such as a cave management plan) are identified in the appropriate sections of this document.

The focus of this General Management Plan is on the developed areas of the park

- South Rim - Hermits Rest, Grand Canyon Village, and Desert View

- North Rim - Bright Angel Point and Walhalla Plateau

- Tuweep

- Corridor trails - primarily the Bright Angel Trail, the North and South Kaibab Trails, the River Trail, and the Old Bright Angel Trail

This General Management Plan is the culmination of a four-year process that has included extensive efforts to involve local citizens, American Indian tribes, and public and private agencies. The environmental impacts of implementing this plan were analyzed in a Draft General Management Plan and Environmental Impact Statement, which was on public review from March 13 to May 11, 1995. An abbreviated Final General Management Plan and Environmental Impact Statement was released for public review on July 21, 1995. A record of decision supporting the selection of the proposed action as the approved plan was signed on August 21, 1995.

\section{PARK PuRPose}

The purpose of Grand Canyon National Park is based on the legislation establishing the park and the legislation governing the National Park Service.

As a place of national and global importance, Grand Canyon National Park is to be managed to

- preserve and protect its natural and cultural resources and ecological processes, as well as its scenic, aesthetic, and scientific values 
- provide opportunities for visitors to experience and understand the environmental interrelationships, resources, and values of the Grand Canyon without impairing the resources

\section{PARK Significance}

Grand Canyon National Park is nationally or internationally significant for the following reasons.

\section{World HeRItage Site}

As a world heritage site, the Grand Canyon is recognized as a place of universal value, containing superlative natural and cultural features that should be preserved as part of the heritage of all people. The Grand Canyon is unusual in meeting both natural and cultural resource criteria for designation as a world heritage site.

\section{Natural Resources / Natural Ecosystem Processes}

The great biological diversity of the park includes examples of five of the seven life zones and elements of three of the four deserts in North America (the Great Basin, Sonoran, and Mojave).

The park serves as an ecological refuge, with relatively undisturbed remnants of dwindling ecosystems (such as boreal forest and desert riparian communities), and numerous rare, endemic, or specially protected (threatened/endangered) plant and animal species. As stated in the establishing legislation, the Grand Canyon is the "greatest eroded canyon in the United States." It is considered one of the finest examples in the world of arid-land erosion.

The Grand Canyon is neither the world's longest nor deepest canyon, but its volume is immense, averaging 4,000 feet deep for its entire length of 277 miles, 6,000 feet deep at its deepest point, and 15 miles wide at its widest.

The geologic record of the Grand Canyon is particularly well-exposed and includes a rich and diverse fossil record. The canyon also contains a great diversity of geological features and rock types.

Numerous caves in the park contain extensive and significant geological, paleontological, archeological, and biological resources.

\section{NATURAL ReSOURCES / Research}

Six research natural areas have been designated in the park (8,845 acres total) to provide opportunities for nondestructive research in areas relatively uninfluenced by humans.

A national natural landmark occurs partially within the park, which encourages recognition and protection of the ponderosa pine habitat of the Kaibab squirrel - a classic example of the process of variation through geographic isolation.

The park is known for nationally significant research in a number of fields (e.g., geology, geomorphology, paleontology, ecology, air quality, aircraft effects, and noise).

The park serves as a natural gene pool, because of its biological diversity and unique conditions. 


\section{Cultural Resources}

Six American Indian groups, represented by eight tribal governments, have close and sacred cultural ties to the Grand Canyon, with some considering the canyon their original homeland and place of origin.

0ver 4,500 years of human occupation have resulted in an extensive archeological record.

The park contains a large number of historic and prehistoric properties and districts that are nationally and internationally significant. Many are eligible for or listed on the National Register of Historic Places; many are also designated as national historic landmarks.

The Grand Canyon contains nationally significant examples of rustic architecture.

The park has hundreds of miles of established prehistoric and historic routes and trails.

\section{SCenic Qualities And Values}

The Grand Canyon has internationally recognized scenic vistas, qualities, and values. With everchanging and colorful scenery of enormous proportions, it is widely considered one of the world's most beautiful natural areas.

The great variety of scenery includes forests, deserts, canyons, plains, plateaus, volcanic features, and streams and waterfalls.

The Grand Canyon is an excellent place for night sky viewing.

The Grand Canyon's class 1 air quality is extremely important to its scenic quality (i.e., visibility, colors, details).

\section{Natural Quiet And Solitude}

The Grand Canyon is recognized as a place with unusual and noticeable natural quiet, and direct access to numerous opportunities for solitude.

\section{SPIRITUAL/INSPIRATIONAL QUALITIES}

All of the natural, cultural, and scenic qualities of the Grand Canyon, coupled with the canyon's vast size, give rise to inspirational/spiritual values and a sense of timelessness.

\section{ReCreational OPPORTUNities}

A wide diversity of resource-based recreational opportunities and support services help visitors experience, enjoy, and appreciate the park.

The vast majority of the park provides opportunities for wilderness experiences. Hundreds of miles of trails and routes provide access to park resources and diverse recreational opportunities and experiences. The Bright Angel Trail, Kaibab Trail, and River Trail are designated national recreation trails as part of the national trails system. The Arizona Trail also passes through the park.

The Colorado River, as it flows through the park, provides opportunities for one of the world's premier river experiences, including one of the longest stretches of navigable white water on earth.

\section{Potential Designations}

Over 1 million acres in the park meet the criteria for wilderness designation as part of the national wilderness preservation system. If combined with over 400,000 additional acres of 
proposed or designated wilderness contiguous to the park boundary, this area could become one of the largest, primarily desert wilderness areas in the United States.

The Colorado River and most of its tributaries in the park meet the criteria for wild river designation as part of the national wild and scenic rivers system.

\section{Grand Canyon national Park: A Vision for the Future}

Grand Canyon National Park is a place of tremendous beauty, peace, and scenic grandeur, as well as a place of vast natural and cultural interest. The canyon is one of the world's most spectacular products of the combined natural forces of uplift and erosion, and as a world heritage site, it has been identified as a place of universal value to all people.

In order to protect this magnificent place, the park should be managed to ensure the preservation of its ecological processes and its historical and archeological resources. Proposed wilderness areas both in and adjacent to the park should be managed as wilderness, and appropriate adaptive reuse of historic resources should be encouraged, while the historical integrity of the cultural landscape is preserved.

Visitor use should be carefully managed in ways that ensure diverse opportunities are provided from solitary wilderness experiences where one feels far from development, to social experiences where a variety of visitor services and conveniences are offered. The unique qualities of each area of the park and its immediate surroundings should be preserved and enhanced to heighten the distinctly different visitor opportunities. All interpretive/educational themes should be represented in the most appropriate locations and manner to educate visitors who have diverse interests and backgrounds.

Any development should be a model of excellence in planning and management, and it should reflect the preservation of park resources and values. New development should be compatible with the historic setting and architecture, as well as being energy efficient, including the use of alternative energy sources and transportation methods.

The park should work cooperatively with surrounding entities to encourage planning and management actions outside the park's boundaries that are compatible with those inside the park. Planning should be done regionally so concepts developed in the park can be linked to adjacent surrounding areas. The defined visitor experience for particular park areas should be carried over to adjacent lands. Information concerning the entire region should be provided and should explain visitor use management strategies, resource sensitivity, and interpretation, as well as help respond to general visitor needs. 


\section{PARK Vision StatementS}

The vision statements for Grand Canyon National Park convey the essence of the park's qualities and desired future conditions. The statements are built on the park's purpose, significance, and applicable legislation, as well as on public comments, consultations with American Indians, and principles of sustainable resource and visitor management. The visions affirm what must be preserved, as well as what types of experiences visitors should be able to expect. The visions and management objectives, along with the purpose and significance statements, provide the basis for the plan, and they set the direction for future management decisions that are not specifically addressed in the plan.

Even though the National Park Service, the U.S. Forest Service (USFS), and the Bureau of Land Management (BLM) have different congressional mandates, they all share a unified vision when addressing the management of visitor use and the preservation of natural resources on lands adjacent to Grand Canyon.

\section{SOUTH RIM}

The South Rim presents opportunities for visitors that are different from those available in other park areas. Of utmost importance is direct access to the rim, where panoramas of the canyon provide the park's aesthetic, inspirational, and emotional appeal - some of the main reasons people visit the park. The South Rim should remain the focus for most park visitors, with diverse opportunities to view the canyon. It should also provide access to areas that allow people to have solitary experiences.

The South Rim should accommodate large numbers of visitors, but dense crowds and related conflicts and resource impacts should be minimized. Visitors should be able to experience solitude in natural settings as well as social exchange in developed areas. For access to such areas, the West Rim and East Rim Drives should be meandering, rural roads that lead to overlooks where visitors can get away from the more urbanized areas of the Grand Canyon Village.

The South Rim should provide parkwide orientation and introduce visitors to all the park's educational themes. This area's historical and archeological resources are so extensive, and the American Indian cultural heritage so rich, that interpretation of these aspects of the park should be a strong component of South Rim programs. In addition, historic resources should be appropriately used and their integrity maintained.

The South Rim should be a model of excellence in planning and management. Alternative means of transportation - walking, biking, or using convenient public transit - should be encouraged. To minimize new disturbance, necessary services and facilities should be provided in existing disturbed areas wherever possible, or outside the park. Any new development should be cost-effective, water-conserving, and energy-efficient, thus reflecting sustainable design concepts.

The park should work cooperatively with the community of Tusayan, Kaibab National Forest, and all other affected entities near the park to encourage compatible, aesthetic, and well-planned development and recreational opportunities and to provide high-quality visitor information and services.

\section{NORTH RIM}

The serene and beautiful natural environment, the sweeping canyon views, and a relaxed, uncrowded feeling are the prime qualities of the North Rim. To ensure that these qualities are 
preserved, the North Rim's natural, scenic, and cultural resources should be preserved. The North Rim and the adjacent national forest lands should maintain a low-key and uncrowded atmosphere that offers visitors opportunities to be intimately involved with the environment.

Any visitor support and administrative facilities and services should be sited to maintain desired visitor experiences and to preserve the largely undisturbed setting. Park roads should be maintained as meandering, scenic drives planned for visitors to view the park environment at a slow pace.

Visitors should be able to experience natural sights and sounds with little or no intrusion from other people in many areas of the North Rim. Day hiking opportunities should be provided, and trails should be maintained through forested and developed areas.

The National Park Service should work cooperatively with Kaibab National Forest to ensure that plans for the management and use of adjacent lands consider the preservation of park resources and provide the same low key, uncrowded visitor experience that is envisioned for the park.

At the same time cooperative work should be done so that the Forest Service supplements and diversifies the visitor experiences provided in the area, especially recreational uses that may be inappropriate in the park but that would be acceptable on national forest lands. This cooperative effort must recognize the different congressional mandates and missions of the Park Service and the Forest Service.

\section{TUWEEP}

Tuweep is unique within the Grand Canyon because it is remote yet still accessible by car. It has spectacular views of Lava Falls, and its highly sensitive natural resources require protection. Even though Tuweep is accessible by car, this area should continue to provide uncrowded, semi-primitive experiences that are dominated by nature and solitude. Visitor facilities should remain minimal, and the ranger station should retain its historic character but also reflect sustainable design principles.

The park should work cooperatively with the state of Arizona, Mohave County, the Bureau of Land Management, Lake Mead National Recreation Area, and other regional entities to ensure that lands outside the park remain uncrowded, that roads and facilities are semiprimitive, and that mining, grazing, and other land uses do not adversely affect Tuweep.

\section{CORRIDOR TRaILS}

The corridor trails are the main transportation routes for most visitors into the inner canyon. Rustic facilities have historically been provided along the trails to meet visitor needs. For over a hundred years mules have carried visitors into the canyon, hauled supplies, and helped with trail maintenance.

The traditional character of the trails should be maintained, and mule use should be allowed to continue. However, crowding, visitor use conflicts, and resource impacts should be minimized. Services, such as drinking water and toilets, should continue to be provided at critical locations for visitor safety and reduced environmental impacts.

Phantom Ranch should continue as a small rustic historic ranch where visitors can experience the inner canyon. 


\section{UNDEVELOPED AREAS}

Over $90 \%$ of the park is proposed for wilderness. These areas offer visitors opportunities for solitude and primitive recreation. The management of these areas should preserve the wilderness values and character. Nonwilderness undeveloped areas should continue to serve primarily as primitive thresholds to wilderness.

Visitors traveling through the canyon on the Colorado River should have the opportunity for a variety of personal outdoor experiences, ranging from solitary to social. Visitors should be able to continue to experience the river corridor with as little influence from the modern world as possible. The river experience should help visitors to intimately relate to the majesty of the canyon.

\section{MANAGEMENT OBJECTIVES}

The management objectives for Grand Canyon National Park, which are based on the park visions, set the direction for future park management. The objectives describe desired conditions to be achieved.

\section{INTERNATIONAL SIGNIFICANCE}

- Manage the park to preserve its integrity as a world heritage site with natural and cultural resources of national and international significance.

\section{Natural And Cultural Resources}

- Preserve, protect, and interpret the park's natural and scenic resources and values, and its ecological processes.

- Preserve, manage, and interpret park cultural resources (archeological, ethnographic, architectural, and historic resources, trails, and cultural landscapes) for the benefit of present and future generations.

- Preserve, protect, and improve air quality and related values such as visibility.

- Manage visitor use, development, and support services to protect the park's resources and values.

- Preserve and protect the genetic integrity and species composition within the park, consistent with natural ecosystem processes.

- To the maximum extent possible, restore altered ecosystems to their natural conditions. In managing naturalized ecosystems, ensure the preservation of native components through the active management of nonnative components and processes.

- Manage ecosystems to preserve critical processes and linkages that ensure the preservation of rare, endemic, and specially protected (threatened/endangered) plant and animal species.

- Protect the natural quiet and solitude of the park, and mitigate or eliminate the effects of activities causing excessive or unnecessary noise in, over, or adjacent to the park.

- Preserve natural spring and stream flows and water quality. Withdraw only the minimum water necessary to meet park purposes. To the maximum extent feasible, strive to meet increases in water demand by conserving and reusing water. 
- Provide opportunities for scientific study and research focused on the Grand Canyon, consistent with resource protection and park purposes.

- Inventory, monitor, and maintain data on park natural and cultural resources and values, and utilize this information in the most effective ways possible to facilitate park management decisions to better preserve the park.

- Clearly delineate and maintain the park boundary to protect park resources and values.

- Identify and evaluate all cultural properties within the park for inclusion on the National Register of Historic Places.

- Collect ethnographic data and develop ethnohistories for the Havasupai, Hopi, Hualapai, Navajo, Southern Paiute, and Zuni peoples concerning their associations with the Grand Canyon, as appropriate, in order to preserve, protect, and interpret park resources and values important to diverse American Indian cultures, including significant, sacred, and traditional use areas.

\section{Wilderness And Wild River ManAgement}

- Manage areas meeting the criteria for wilderness designation as wilderness. Actively pursue the designation of these lands as part of the national wilderness preservation system.

- Manage the Colorado River corridor through Grand Canyon National Park to protect and preserve the resource in a wild and primitive condition. Actively pursue the designation of eligible segments of the Colorado River and its tributaries as part of the national wild and scenic rivers system.

\section{VISITOR EXPERIENCE}

- Provide a diverse range of quality visitor experiences, as appropriate, based on the resources and values of the Grand Canyon, compatible with the protection of those resources and values.

- Provide access that is appropriate and consistent with the character and nature of each landscape unit and the desired visitor experience.

- Consistent with park purposes and the characteristics of each landscape unit, preserve and protect the maximum opportunities in every landscape unit of the park for visitors to experience the solitude, natural conditions, primitiveness, remoteness, and inspirational value of the Grand Canyon.

- Provide equal access to programs, activities, experiences, and recreational opportunities for individuals with disabilities, as appropriate and consistent with the levels of development and inherent levels of access in areas within the park.

- Provide a wide range of interpretive opportunities and information services to best assist, inform, educate, and challenge visitors.

- Educate and influence the public through positive action to preserve and protect the world they live in, including but not limited to the park.

- Provide a safe, efficient, and environmentally sensitive transportation system for visitors, employees, and residents, consistent with management zoning and resource considerations. Emphasize nonmotorized modes of transportation wherever feasible.

- Develop visitor use management strategies to enhance the visitor experience while minimizing crowding, conflicts, and resource impacts. 
- Provide visitor and employee facilities and services, as necessary and appropriate, in or adjacent to areas dedicated to those uses or in appropriate disturbed areas.

\section{FACILITY DESIGN}

- Consistent with its purpose, strive to make Grand Canyon National Park a model of excellence in sustainable design and management through such means as energy efficiency, conservation, compatibility with historic setting and architecture, recycling, accessibility, and the use of alternative energy sources.

- Encourage appropriate use and adaptive reuse of historic structures, while preserving historic integrity.

- Ensure that development and facilities within the park are necessary for park purposes.

- Design high-quality facilities that exemplify visual consistency and appropriateness.

- Ensure that park developments and operations do not adversely affect park resources and environments, except where absolutely necessary to provide reasonable visitor access and experiences.

\section{REgIONAL ISSUES}

- Understand, assess, and consider the effects of park decisions outside the park as well as inside.

- Upon request, work cooperatively to assist local American Indians in planning, developing, and managing lands adjoining the park in a mutually compatible manner.

- Work cooperatively with appropriate entities to encourage compatible, aesthetic, and planned development and recreational opportunities outside park boundaries, and to provide information, orientation, and services to visitors.

- Carry the NPS concern for the environment beyond the boundaries of the park, including the protection of park resources and values from external influences.

\section{SOUth Rim Management ObJectives}

The South Rim is considered to be bounded on the west by Hermits Rest, on the east by Desert View, on the north by the canyon rim, and on the south by the park boundary. The following objectives for the South Rim are in addition to the overall park objectives.

\section{Visitor Experience}

- Identify and develop an appropriate range of visitor experiences, opportunities, and access that will accommodate a variety of visitor expectations, abilities, and commitment levels.

- Provide viewing opportunities of the canyon, access to views and trails, and interpretation and information, recognizing that these are the most important elements of the visitor experience on the South Rim.

- Maintain the South Rim from Hermits Rest to Desert View as the focus for the majority of visitor use in the park, including major visitor facilities and accommodations.

\section{Cultural Resources}

- Utilize the extensive cultural resources of the South Rim as a strong component of the interpretive program, including the interpretation of American Indian cultures. 


\section{Development}

- Develop and promote the use of foot trails, bicycle paths, and public transportation to provide convenient and efficient movement of visitors, employees, and residents within Grand Canyon Village and between major points of interest.

- Maintain and enhance the meandering, rural character of West Rim and East Rim Drives, including the feeling that one is removed from the developments of Grand Canyon Village and Desert View. Maintain the existing large undisturbed areas along West Rim Drive.

\section{North Rim Management ObJectives}

The North Rim is considered to include all park lands north of the canyon rim from Walhalla Plateau west to Swamp Point. The following objectives for the North Rim are in addition to the overall park objectives.

\section{Visitor Experience}

- Maintain a slow pace, low-key atmosphere and historic setting on the North Rim, including the Bright Angel peninsula, allowing visitors to have an intimate involvement with the environment. Preserve the uncrowded atmosphere of limited or no development in all areas. Ensure that park roads are maintained as meandering, scenic roads that are designed for viewing the park environment at a slow speed.

- Ensure that visitors, even on the Bright Angel peninsula, are within a short distance of areas where the sights and sounds of other people create little or no intrusion on their experience.

- Provide a primitive winter experience consistent with historic winter recreational opportunities.

\section{Access}

- Emphasize the natural environment and slow pace of the visitor experience in providing all access to the North Rim, and be consistent with the characteristics of the particular destination inside the park.

- Provide opportunities for day hikes on maintained trails through the forest environment away from developed areas.

Development

- Limit all visitor, administrative, and support facilities and services, including overnight accommodations, to maintain the integrity of the desired visitor experience and historic setting.

- Maintain large undisturbed areas on the Bright Angel peninsula.

\section{TuWeep Management OBJectives}

Tuweep is considered to include park lands within 150 feet of the roads to Toroweap 0verlook and the Lava Falls trailhead, including those destinations, and the Tuweep ranger station development. The following objectives for Tuweep are in addition to the overall park objectives. 
- Maintain Tuweep as a place for an uncrowded, rustic, and remote experience that is dominated by nature and solitude.

- Maintain park roads at Tuweep in their current primitive, unpaved condition, and encourage access roads outside the park to be consistent with the vehicular experience to be provided inside the park.

\section{Corridor Trails Management Objectives}

Corridor trails include the Bright Angel Trail, North and South Kaibab Trails, River Trail, Old Bright Angel Trail, and the Tonto Trail between the Bright Angel and South Kaibab Trails. The following objectives for the corridor trails are in addition to the overall park objectives.

\section{Visitor Experience}

- Where livestock and visitors share the same trails and areas, minimize conflicts and resource impacts, and enhance safety.

- Provide a high level of NPS management presence to enhance the visitor experience and safety, and to protect park resources and values.

- Provide a quality backcountry experience consistent with historic uses of the cross-canyon corridor.

\section{Development}

- Provide facilities only at currently developed areas within the cross-canyon corridor.

- Provide only basic services and facilities that support resource preservation and visitor safety, and that preserve an experience dominated by the natural environment and historic setting, design, and uses.

- Minimize the intrusion of the sights and sounds of facilities and developments on the visitor experience (for example, lights or generators should not be seen or heard by visitors in campgrounds). Maintain and enhance the historic setting.

\section{Maintenance}

- Maintain the Bright Angel, North Kaibab, South Kaibab, and River Trails to accommodate high levels of backcountry visitor use.

- Minimize and mitigate the impacts of trail maintenance activities, such as borrow pits, on the environment away from the immediate trail.

\section{Undeveloped Area Management Objectives}

Undeveloped areas are considered to be all areas within the park boundaries not within the areas described for the South Rim, North Rim, Tuweep, or corridor trails. The following objectives are in addition to the overall park objectives.

- Manage and monitor visitor use and park resources in the park's undeveloped areas to preserve and protect natural and cultural resources and ecosystem processes, and to preserve and maintain a wilderness experience or, where an area is not proposed for wilderness, a primitive experience. 
- Establish indicators and standards for desired visitor experiences and resource conditions, monitor the condition of those indicators on a regular basis, and take action to meet the standards if they are not being met.

- Provide a variety of primitive recreational opportunities consistent with wilderness and NPS policies on accessibility. In deciding which opportunities would be provided in the undeveloped areas of the park, consider recreational opportunities available outside the park, as well as opportunities available in developed areas of the park.

- Conduct administrative activities, including research, search-and-rescue, emergencies, and fire management, in a manner that is consistent with NPS policies regarding wilderness management and the use of the minimum tool in wilderness areas.

- Maintain roads designated open to public or administrative motor vehicle use in undeveloped areas in an unpaved condition without major improvements. Only consider improvements that reduce resource impacts in keeping the road minimally open for vehicle use. Revegetate all roads not designated for vehicle use, or convert them to trails as appropriate.

- Consistent with the above goals, reduce conflicts among undeveloped area users, including river, hiker, stock, motorized and nonmotorized users.

- Provide a wilderness river experience on the Colorado River (this objective will not affect decisions regarding the use of motorboats on the river). 


\section{AN OVERVIEW OF THE PLAN}

\section{SUMMARY OF PARKWIDE ACTIONS}

This General Management Plan for Grand Canyon National Park emphasizes the park's regional context, and proposals for resource preservation and visitor use take into account environmental effects on the park as well as the region. Planning outside the park will be done cooperatively, with an emphasis on disseminating information, preserving regional and park resources, and providing quality visitor experiences.

The National Park Service will work jointly with adjacent entities to provide for many park needs outside park boundaries. The most appropriate locations for facilities will be considered in a regional context, taking into consideration principles of sustainable design and the need to preserve resources while providing for a quality visitor experience. Alternative modes of transportation (public transit, hiking, and biking) will be emphasized within the park.

To minimize impacts on natural and cultural resources, existing structures will be adaptively reused, and required new facilities will be built in previously disturbed areas wherever possible. Some disturbed areas will be revegetated.

The visitor experience within and adjacent to the park will be defined by the unique qualities of each area. To ensure a quality experience, the number of visitors admitted to certain areas will be limited during peak visitation periods based on the desired visitor experience and the need to protect resources. The process for determining use limitations will be the same throughout all developed areas of the park; however, visitor levels in specific areas will vary considerably, and use will be limited sooner in some areas than in others.

Day visitation on the South Rim and the corridor trails will not need to be limited during the life of this plan. Day visitation on the North Rim will probably need to be limited sometime between 2005 and 2010, depending on the effectiveness of management actions. Day use at Tuweep may be limited during peak times. In areas where permits become necessary, visitors will be able to obtain them ahead of time; permits will be checked at park entrances.

A monitoring system will be established to measure resource impacts, facility use, visitor satisfaction, and levels of visitor attendance in each park developed area. Visitor use limits will be adjusted as needed, based on the monitoring program.

To preserve resources and to ensure a quality visitor experience, most of the park's developed areas will be accessible only by public transit, hiking, or biking. Private vehicles (tour buses, cars, and RVs) will only be allowed in specific areas. The public transit, bikeway, and pedestrian system will be significantly expanded.

Interpretive programs will focus on the significant resources of Grand Canyon, as well as regional conservation and preservation issues. Overnight accommodations will be expanded on

the South and North Rims, primarily by adaptively reusing structures. 


\section{LAND Protection}

\section{MANAGEMENT ZONES}

The NPS Management Policies (1988) require that general management plans

prescribe a system of management zoning for park lands and waters to designate where various strategies for management and use will best fulfill management objectives and achieve the purpose of the park. The delineation of management zones will be based on an evaluation of the congressionally established purposes of the park; the nature of the park's natural and cultural resources; all past, existing, and anticipated uses; and park management objectives. This prescriptive zoning will consider the capability of lands to support identified uses and will be used as a framework for specific planning and management decisions on use and development of the park. (NPS 1988d 2:7).

\section{- Natural Zone}

As defined in the NPS Management Policies, the natural zone includes lands and waters that will be managed to conserve natural resources and ecological processes and to provide for their use and enjoyment by the public in ways that do not adversely affect these resources and processes. Development in the natural zone will be limited to dispersed recreational and essential management facilities that have no adverse effect on scenic quality and natural processes and that are essential for management, use, and appreciation of natural resources (NPS 1988d 2:7).

Lands proposed for wilderness or potential wilderness designation (see page 60), the established Havasupai Use Lands, the Colorado River, and undeveloped areas on the South Rim are all within the natural zone.

\section{- Cultural Zone}

This zone includes lands that will be managed for the preservation, protection, and interpretation of cultural resources and their settings and to provide for their use and enjoyment by the public. Cultural resources that are key to the purposes of the park will be included in this zone (NPS 1988d 2:7).

All designated historical districts in the cultural zone being dealt with in the plan are within the park's developed areas. Compared to the geographic extent of the other zones, these districts are small.

\section{- Development Zone}

The development zone, as defined in the Management Policies, includes lands that will be managed to provide and maintain facilities serving park managers and visitors. It will include areas where park development or intensive use may substantially alter the natural environment or the setting for culturally significant resources. Impacts associated with such development will be mitigated to the greatest extent possible. The development zone will encompass the facilities themselves and all associated lands directly modified as a result of their continuing management 
and use. Development zones will be restricted to the smallest area necessary to accommodate required development and use (NPS 1988d 2:8).

Park Developed Areas: The following seven distinct developed areas are included in the development zone:

- South Rim

Hermits Rest: This area extends from the paved parking area on the east to the Hermit trailhead on the west, and it includes all the structures, walkways, and roads in-between.

Grand Canyon Village: The village is generally bounded on the west by Rowe Well Road (but includes Supai Camp and the wastewater lagoons), on the south by power- and sewerline corridors and by Center Road (but includes the helibase area and the landfill area), on the east by the south entrance road (but includes the Southgate area and the South Kaibab trailhead area), and on the north by the canyon rim.

Tusayan Museum: The museum area includes the parking lot, the museum building, the adjacent residence, and the area between them.

Desert View: This developed area is bounded on the west, north, and east by the canyon rim; the south boundary is an imaginary line from the rim to the west side of the current entrance station, then just south of the entrance station and the employee housing area along sewerlines to the lagoons, and then to the rim.

- North Rim - The North Rim developed area includes the entire Bright Angel peninsula, from the wastewater treatment plant south, plus the CC Hill and the North Kaibab trailhead areas.

- Tuweep - At Tuweep the developed area consists of the ranger station, the water catchment system, the outbuildings (including the generator shed), the area between these facilities, the campground, and the unpaved road into Tuweep.

- Corridor Trails - Phantom Ranch is bounded on the east and west by the canyon walls, on the north by the hiker dorms, and on the south by the Colorado River.

Actions are also proposed for Lees Ferry, which is an existing development zone of Glen Canyon National Recreation Area. Because Grand Canyon National Park rangers are stationed at Lees Ferry, plan proposals relating to operations at that site will be considered in an amendment to the 1985 Lees Ferry Development Concept Plan.

Transportation Subzones. Transportation subzones connect development zones and include primarily paved road corridors and rail corridors to a width appropriate for safe travel. The following areas are designated transportation subzones:

- West Rim Drive - West Rim Drive extends from Grand Canyon Village to Hermits Rest, plus existing overlooks, parking areas, and areas immediately adjacent to West Rim Drive that would be suitable for a bike/pedestrian trail.

- East Rim Drive - East Rim Drive extends from Grand Canyon Village to the east entrance (excluding the Desert View developed area), plus existing overlooks, access roads to 
overlooks, picnic areas, parking areas, and areas adjacent to East Rim Drive, particularly on the north side, that would be suitable for a bike/pedestrian trail

- South Entrance Road - The south entrance road links the south entrance and the Grand Canyon Village developed area, plus the following corridors: Rowe Well Road, the old entrance roadbed west of the existing entrance road, and the existing railroad corridor along Bright Angel Wash.

- North Entrance Road - The north entrance road links the north entrance and the North Rim developed area.

- Walhalla Plateau Scenic Drives (North Rim) - Scenic roadways extend from the north entrance road to Point Imperial and Cape Royal, including existing overlooks and parking areas, plus areas adjacent to these roads (and outside recommended wilderness areas) that would be suitable for bike/pedestrian trails.

Utility Subzone. The utility subzone of the development zone includes all utility corridors, such as the existing powerline corridor into Grand Canyon Village from the south, the corridors from Grand Canyon Village to Desert View and to Hermits Rest, and from the north park entrance to Bright Angel Point. Their width is determined by the spatial needs of the particular type of utility (such as, water, sewer, or power).

\section{Proposed WiLderness}

Over $90 \%$ of the park will be managed as wilderness, in accordance with the park's 1993 wilderness proposal. Areas currently excluded from proposed wilderness include (1) several dirt roads throughout the park, (2) on the South Rim the area from Hermits Rest to Desert View, (3) Bright Angel Point on the North Rim (300' on either side of paved roads and 150' on either side of unpaved roads), (4) the Tuweep developed area, and (5) the corridor trails.

\section{BOUNDARY CONSIDERATIONS}

As part of the planning process, the National Park Service considered what modifications of external boundaries might be necessary to carry out park purposes (NPS 1988d 2:8). Studies of potential boundary adjustments may result in recommendations to revise boundaries to accomplish the following:

- to include significant resources or opportunities for public enjoyment related to the purposes of the park

- to address operational and management issues such as access and boundary identification by topographic or other natural features or roads

- to protect park resources critical to fulfilling the park's purposes

Recommendations to expand park boundaries will be preceded by determinations that

- the added lands will be feasible to administer considering size, configuration, ownership, costs, and other factors

- $\quad$ other alternatives for management and resource protection are not adequate (NPS 1988 2:8)

The scoping process for this plan identified a concern regarding the long-term protection of park interests relative to the airstrip at Tuweep. This concern will be addressed in cooperation with affected landowners, and subsequently a determination about conducting a boundary study for this area to determine the desirability and feasibility of adjusting the park boundary will be made. 


\section{NATURAL RESOURCE MANAGEMENT}

\section{Air Quality And NoISE}

Air quality and visibility in the park will be improved by cooperatively reducing in-park and external emission sources. The intent is to improve the visitor experience at overlooks during the day and to add to the enjoyment of the night sky.

All permits and licenses required for operating commercial and transit vehicles within the park will incorporate standards for reducing air and noise emissions to the maximum extent feasible, phased in over the quickest reasonable time period. Bus operators will be required to turn off their engines when parked, continuing the current restrictions.

Safe bikeway systems will be provided to encourage the use of alternative modes of transportation.

Employee shuttle services will be established for people working on the South and North Rims, and employees will be encouraged to use them. The service on the South Rim will extend into the Tusayan area. In addition, the Park Service will encourage the development of a regional park employee shuttle service. Walking and biking trails will also be expanded.

All trains will be required to meet federally mandated train air emission standards and to minimize the use of train whistles and bells, as safety allows.

The Park Service will encourage the use of clean fuels in Tusayan and throughout the South and North Rims for vehicles and heating systems.

No additional wood-burning stoves or fireplaces will be allowed in the park, and all replacements will have to meet EPA standards. Historic uses such as the fireplace at El Tovar will be exempt from these standards. Campfires will still be allowed in the campground.

The Park Service will discourage changes at the Grand Canyon Airport in Tusayan that would result in increased noise pollution in the park. Any needed expansion of airport facilities will be encouraged to be located farther from the park.

\section{Vegetation / WiLdLife / ECOSYSTEMS}

The Park Service will develop and implement an ecosystem approach to managing threatened and endangered species, and it will institute an active research and recovery program. An ecosystem research program will be developed, based on a baseline inventory and long-term monitoring program. All specimens collected and retained from park lands will be cataloged.

A vegetation management plan will be developed and implemented. The plan will focus on removing or preventing hazardous tree situations, rehabilitating and revegetating disturbed areas, removing nonnative species, reestablishing native landscaping, promoting healthy native landscaping through appropriate plant care techniques, and using low-impact techniques to manage overlooks and vistas. Native and self-sustaining plant materials from the park's gene pool will be used wherever feasible.

Landscaping around historic structures will maintain the character of the cultural landscape and will use naturally occurring plants. Vegetation loss will be a primary consideration in evaluating development proposals, and little loss will be tolerated. If projects result in a loss of vegetation, the revegetation of other disturbed areas may be required, acre for acre. 
The need to use borrow pits for trail maintenance will be minimized; trail maintenance materials will be brought from outside the park whenever possible.

The natural role of fire within park ecosystems will be restored within the constraints specified in the park's Fire Management Plan.

The following additional studies and surveys will be required for the management of natural resources:

- a parkwide relict area survey for unaltered natural vegetation and biotic communities

- a parkwide soil map and classification system to the series level or to the soil type

- effects of fire exclusion and prescribed fire on park wildlife and the representative vegetation communities

- the natural fire regime for plant communities (by examining fire scars on presettlement trees)

- the biology of federally listed and sensitive species of plants and animals

- the status and trends of nonnative species within the park

- the impacts that nonnative species have on native wildlife and mitigation measures

- park wildlife species inventory and assessment

- an impact assessment of urbanization on wildlife

- feasibility studies on reintroducing extirpated wildlife

- a wetlands delineation survey

- surveys of potential erosion areas at archeological sites, campgrounds, and along trails

\section{WATER RESOURCES}

Water resource management actions will include reducing the use of water in the park, conserving ground and surface water resources, instituting water quality and flow monitoring, understanding the park's hydrography, and protecting park water rights and the water supply capacity.

Flow monitoring of inner-canyon springs and creeks will be initiated in some new areas and continued in other areas. Unless an alternative water source for the South Rim is provided, the transcanyon waterline will be replaced from Phantom Ranch to Cottonwood.

Research and monitoring will be conducted to better understand and manage the park's water resources and hydrogeology. Measures will be taken to ensure that well drilling or other outside water uses do not adversely affect park water resources.

Natural water quality and flows will be perpetuated throughout the park, except for the Colorado River where flows will be managed to maintain the natural values of the river corridor. Water withdrawals needed for administrative use will be limited to current levels and will be done in a way to minimize impacts to park resources. This may include investigation of the feasibility of alternative water sources to Roaring Springs, or modifying the transcanyon pipeline so that all water not needed for park administrative purposes is returned to the flow of Roaring Springs and is no longer discharged at Indian Garden.

The National Park Service will use water rights where appropriate to protect park resources and administrative uses necessary to meet the purposes of the park. To do so, the park will participate in state adjudications of water rights, seek negotiated settlements to protect park water rights, and if necessary, seek injunctive relief when park water resources or rights are being adversely affected. 
For facilities proposed in the Tusayan area (housing, a gateway information center, etc.), water will be provided from the park system unless other sources are developed that have fewer impacts on park water resources.

Minimum flow requirements in Bright Angel Creek for aquatic wildlife and recreational activities during droughts will be established. Water withdrawals may have to be curtailed to meet these requirements. Water consumption (measured as gallons per visitor pumped to the rim) will be reduced from 43 in 1994 to 20 in 2010 if the Roaring Springs source is retained.

The following additional studies and surveys will be required for the management of water resources:

- the impact of water diversion or groundwater withdrawal on seeps, springs, and hanging gardens

- the impact of water diversion or groundwater withdrawal on stream channels

- quantification of flows and water-related values at various springs and streams in order to participate effectively in future water right adjudications

- an instream flow study for Garden Creek

- identification of areas where water resources are excessively impacted by management activities and/or visitor use

- research and monitoring of the resources of the Colorado River corridor to obtain information to guide its management

\section{SCENIC RESOURCES}

Components of the human environment that adversely affect scenic resources (for example, powerlines, lights, airport beacons, trash bins) will be identified, and the Park Service will work with the necessary entities to minimize or reduce such visual intrusions. The character of historic districts will be enhanced by removing many nonhistoric structures and placing needed new facilities in areas that will not detract from the historic character. Overlooks will be maintained for resource protection and scenic quality. Existing and new light sources will be shielded to reduce light pollution at night.

\section{Cave Management}

A cave management plan will be developed to address issues such as the following:

- a permit system

- specific standards, indicators, and monitoring programs, and a method to address problems when standards are not met

- active or passive management by the National Park Service or cooperative management by another entity, such as the Cave Research Foundation

- use limits or restrictions, if necessary, including party size limits

\section{Cultural Resource Management}

Significant cultural resources (archeological, historic, and ethnographic) will be preserved and protected. 
On the South Rim a new museum collection storage and research facility, with appropriate environmental controls, security, and fire protection, will be constructed near the NPS maintenance area.

Cultural landscape studies will be conducted to evaluate the significance of historic landscapes in the park and to determine their character-defining features. The use of native building materials and the physical layout of developed areas in harmony with the natural contours of the land has allowed many elements of the built environment to blend with their natural surroundings. The settings of several historic districts, including Grand Canyon Village, are characterized by natural and historic landscaping, roads, and footpaths. In some cases historic natural landscaping was designed in such a way as to give a natural appearance using indigenous trees and shrubs. Associated with some historic footpaths, overlooks, and roads are a number of rustic stone curbs, headwalls, retaining walls, and culverts. Any changes to significant historic landscapes will be undertaken in accordance with historic preservation standards and NPS Management Policies, and significant character-defining features will be retained.

The Park Service will develop an integrated database for archeological, historic, and ethnographic resources, including cultural landscapes and museum objects. This database will be incorporated into the NPS archeological resources inventory, the historic property preservation database, and the ethnographic resources inventory. Updates on the documents and the database will be done regularly. Research by an interdisciplinary team will support planning and compliance actions.

A comprehensive program to preserve and maintain archeological, historical, and ethnographic resources will be implemented. The primary purposes of these studies will be to identify, document, and protect these resources. This program will also meet the requirements of the Archeological Resources Protection Act, the National Historic Preservation Act, the American Indian Freedom of Religion Act, and the Native American Graves Protection and Repatriation Act. In addition, an active stewardship program will be organized and encouraged to manage cultural resources, including the adaptive reuse of historic structures.

A memorandum of agreement will be executed with each associated American Indian tribe to detail consultation procedures for actions that might affect ethnographic resources and to ensure their protection. Each memorandum of agreement will address not only the treatment of ethnographic resources in the broadest sense, but also human remains and objects protected by the Native American Graves Protection and Repatriation Act. In all NPS actions outside the park where the Park Service is a cooperating agency, the Park Service will take the lead in developing these memoranda of agreement. The confidentiality of all ethnographic information collected in the studies will be ensured when so requested.

A proactive ruins stabilization program will be developed, and sacred sites identified by the tribes will be protected. Sacred sites will also be protected through ongoing consultation and communication with the tribes.

A program will be initiated to complete the survey, inventory, documentation, and evaluation of cultural resources in the park under criteria for listing on the National Register of Historic Places.

The active program for collections management and a high-quality program for cataloging park collections will take place in the new museum collection storage and research facility. In addition, the park will actively seek to improve the quality of its museum collections by both acquiring needed materials and deaccessioning inappropriate ones. 
A comprehensive inventory and data management system will be established for archeological resources, historic structures, cultural landscapes, museum objects, and ethnographic resources. As part of this system, the following will be undertaken:

- a regionally based archeological research plan

- a parkwide archeological assessment and research design

- data recovery at archeological sites in designated campgrounds

- a cultural resource inventory of the park's backcountry

- a comprehensive archeological inventory of park developed areas and immediate adjacent areas

- an archeological inventory of the inner canyon developed areas and trails

- computerized databases of cultural resources

- a comprehensive historic resource study program (including historic resource studies, a park administrative history, historic structure reports, and cultural landscape reports)

- documentation, evaluation, and preparation of nomination forms to the National Register of Historic Places for all CCC improvements in the park.

- a parkwide ethnographic overview and assessment, including a traditional use study

- specific ethnographic studies for each tribe associated with the park

- studies to identify ethnographic resources for resource management and protection purposes, for nomination to the national register, and for interpretive use

- a scope of collections statement

\section{THEMES FOR INTERPRETATION}

An interpretive prospectus for Grand Canyon National Park has been developed in concert with the General Management Plan. When approved, this prospectus will be the first step toward comprehensive interpretive planning for facilities proposed in this plan. The interpretive prospectus will also establish a foundation for future exhibit planning and design, audiovisual production, and publications because it is based on the same set of interpretive themes that have been developed for this plan, as stated below.

Archeology - The ways human beings adapted to a harsh environment, how they utilized the canyon's natural resources, and what environmental and cultural conditions either allowed them to live at the canyon or caused them to move elsewhere offer important analogies for modern people and their interrelationship with the natural environment.

Ethnography - Many American Indians attribute a profound religious and cultural significance to the canyon. It is their sacred and ancestral homeland, a place that remains extremely spiritual to them.

History - The exploration, exploitation, and protection of the Grand Canyon region affected the eventual development of the area.

American Indians lived and continue to live in and around the Grand Canyon, and they continue to play a significant role in the history of the canyon. 
Geology - The Grand Canyon is one of the most spectacular erosional features on the face of the earth. Water, including the Colorado River, and other natural forces are responsible for sculpting the arid landforms visible below the rim. Each of the many rock layers exposed in the canyon responds differently to erosion, giving the canyon its characteristic diversity of shape and color.

The formation of the Grand Canyon and its multiple rock layers was the product of many forces, including uplift and subsidence of the land, erosion, volcanism, and the movement of land masses over large portions of the earth. Understanding the exact timing and sequence of events that carved the canyon still challenges scientists.

The geologic record exposed in the walls of the Grand Canyon - many thousands of feet of sedimentary, igneous, and metamorphic rock - provides an unparalleled view of the geologic history of North America.

Natural Resources - The elevational diversity at the Grand Canyon has resulted in significant climatic variations and biological diversity that are reflected in life zones ranging from the arid lower Sonoran Desert to those typical of forested regions far to the north in Canada.

Park Management - Decisions made about the operation of the park must preserve park resources while providing for the enjoyment of visitors.

Outside activities and influences often threaten the natural and cultural resources and values of the park. The park also affects people and lands outside the park boundaries. The National Park Service works cooperatively with outside interests to identify threats and solutions.

Inspiration and Experience - The Grand Canyon has an aesthetic and emotional appeal that has inspired people to contemplate the significance of nature in the human experience (with examples from the works of artists, writers, and musicians).

The Grand Canyon offers opportunities for solitude, contemplation, and a personal experience of the remarkable resources that make up the canyon and its environments. The whole is diminished if any of these pieces is lost. 


\section{SOUTH RIM}

\section{SUMMARY OF SOUTH RIM ACTIONS}

The vision for the South Rim is to allow visitors direct access to canyon panoramas and to offer a range of visitor experiences - from more social experiences in Grand Canyon Village to solitary experiences elsewhere along the rim.

To achieve this vision, the number of private vehicles parking on the South Rim at any one time will be limited. During peak seasons private vehicles will not be allowed in the village, along the West Rim, or at East Rim overlooks. These areas will become pedestrian spaces where visitors can enjoy the views, learn about the park's interpretive themes, use visitor services, and find secluded spots. A public transit system, along with bike and pedestrian paths, will provide access along the South Rim.

A gateway center in Tusayan and two orientation/information stations in the park - one at Mather Point near the village, and the other at Desert View - will tell visitors about the park.

Overnight lodging will be increased by about $25 \%$ by adaptively reusing existing structures, and the total number of campsites will be increased by about $18 \%$.

Substandard housing units will be replaced with higher density housing in disturbed areas. Additional housing will be developed in cooperation with the U.S. Forest Service outside the park in or near Tusayan.

\section{SOUth Rim Planning Issues}

\section{- Region}

The South Rim lacks a coordinated regional transportation system, and most visitors rely on private vehicles for access to the park; a few visitors arrive by tour bus. High visitor use, particularly in summer, causes traffic congestion outside the park.

There is no information or orientation for visitors before they enter the park. Visitors often arrive at the South Rim without reservations for accommodations, not realizing that facilities are usually full year-round.

Most park visitors on the South Rim pass through the community of Tusayan, which has a number of motels, restaurants, and tourist developments that cater to park visitors. The residents and businesses of Tusayan are actively pursuing local development plans (e.g., the Tusayan Area Plan). The potential expansion of Grand Canyon Airport in Tusayan would also increase visitation to the park.

There are demands for more water outside the park, with the possibility of new wells or requests for more park water.

\section{- Visitor Experience}

The South Rim is too crowded during summer. The road system is heavily congested; confusing traffic routing and signs further confound visitors. Parking for automobiles and buses is inadequate. 
The shuttle system is crowded, and there are too few buses. Routes are inadequate, and the operating season is too short.

The small visitor center is hard for visitors to find. Orientation is inadequate, and outdated exhibits are in overcrowded spaces.

Interpretive facilities, such as the Yavapai Observation Station and Tusayan Museum, are overwhelmed by visitors in the peak season, resulting in inefficient operations. The park's interpretive emphasis is on Euro-American cultures, with little interpretation of American Indian cultures and their relationship to the canyon. Information and interpretation are inadequate for international visitors.

Food services are inadequate, with long waits at all sit-down restaurants in Grand Canyon Village.

Biking is dangerous because no lanes, paths, or trails have been designated.

\section{- Cultural and Natural Resources}

There is potential for archeological and ethnographic resources to be damaged by development. Historic structures in Grand Canyon Village are poorly used.

Vegetation at the most popular overlooks is being trampled by unrestricted use.

Natural quiet is affected by aircraft overflights.

Air quality is poor due to vehicle emissions and wood smoke.

\section{- Utilities}

Water for the South Rim is provided by the transcanyon waterline, which needs costly repairs.

Phone service is inadequate, which limits the effectiveness of visitor communications and regional coordination.

There are too few restrooms. Visitors must use chemical toilets in the village and at some museums, and these facilities are maintenance intensive.

\section{SetTing the South Rim Carrying CaPaCity}

The number of visitors who can be accommodated at park facilities was established based on the size of existing overlooks and rim trails (primary visitor destinations). This limit can easily be modified to account for new information gathered from monitoring or changing conditions. Capacity figures are also based on the visions to be attained or maintained at different developed areas. For example, the visitor densities (visitors per unit area) on the South Rim are higher than they are for the North Rim, although the methodology used for each was the same.

Since overnight capacities are already established by the number of rooms and campsites, the carrying capacity referred to in this plan is a day carrying capacity.

On the South Rim the overlooks and rim trails were determined to be the primary visitor destinations. The carrying capacity for each overlook or trail was derived through the following process:

- generating a detailed inventory and analysis of current visitation for every developed visitor use area on the South Rim

- surveying visitor preferences

- photographing visitor use patterns along with the visitation analysis and surveys at prime and average use times 
- determining the size of each primary and secondary overlook (paved and adjacent disturbed areas)

- categorizing the desired density of visitors at every overlook

- establishing the appropriate number of visitors for each overlook, based on the above information

- determining the potential redistribution of visitors, based on the proposed plan

- correlating the overlook and rim trail carrying capacity with the secondary attractions (for example, restaurants and lodging)

- determining the overall South Rim carrying capacity

\section{HOW Visitors ARRIVE ON THE SOUTH RIM}

- Visitors will receive information packets at home that describe transportation alternatives, visitor services, lodging, etc.

- Visitors may stop at regional gateway information centers at Las Vegas, Phoenix, Williams, and Flagstaff.

- Electronic message signs south of Tusayan and in Cameron will advise travelers about the status of parking on the South Rim.

- Visitors will be encouraged to stop at the gateway orientation center at Tusayan. If the Mather Point parking area is full, visitors may choose to park and ride an NPS or private transit bus into the park.

- Visitors may stop at the Mather Point orientation/transit center (by private vehicle if the lot is open, otherwise by tour or transit bus).

- Visitors parking at Mather Point will ride an NPS shuttle into the village and on West Rim Drive. If parking is not available, visitors will have to park their private vehicles in Tusayan and take a transit service into the park.

- Private vehicles and tour buses will be allowed to access East Rim Drive at all times.

- Overnight guests will be allowed to drive to the designated parking area for their particular lodging unit. Tour buses with overnight guests will be allowed direct access to lodging units to drop off passengers.

\section{ACCESS FOR PeOPLe WITH Disabilities}

All parking lots will conform to federal accessibility standards. Parking with adjoining access aisles will be located next to accessible routes.

Accessible transit vehicles will be made available in transit-only areas, and visitors with disabilities who cannot be adequately accommodated by public transportation will be allowed access by private vehicle.

All trails above the rim will be made as accessible as physical conditions allow, given the fact that the terrain at Grand Canyon is rugged and steep. Actual trail conditions will range from wide paved trails with level grades to narrow unpaved trails with steep grades. Wherever possible, slopes will not exceed 5\% and cross slopes will not exceed $2 \%$. A trail rating system based on the ease of accessibility will be developed. Trails will be rated so that visitors with disabilities know what to expect. 
All nonhistoric buildings will be made fully accessible for persons with disabilities. Every effort will be made to ensure that providing accessibility to historic buildings is balanced with maintaining the historical integrity of each structure. All visitor services will be adapted for visitors with special needs.

\section{VISITOR EXPERIENCE}

\section{Visitor Use Patterns}

To continue providing a quality visitor experience while protecting park resources, and in keeping with the visions and management objectives established for the South Rim, limits will be placed on the number of people who can visit the South Rim at any one time. However, if the visitation assumptions made in this document are reasonably accurate, and if the proposed transportation changes are implemented, then limits are not expected to be necessary until approximately 2015. The transportation changes will improve visitor distribution while still providing opportunities along the South Rim for solitude. The point at which limits will be imposed, once these changes are made, will be when approximately 22,500 visitors are on the South Rim at any one time.

The number of visitors at one time was derived through the carrying capacity process outlined in the special attention box on page 25 . This capacity figure is a day use limit; because it is an estimate, it can be adjusted up or down based on data from future monitoring. The monitoring process will include many of the steps used in originally determining the capacity figures, including surveys of visitors. When monitoring shows that the number of visitors is nearing the stage where experiences or resources are beginning to be negatively impacted, then the capacity will have been reached. It is currently thought this will occur with about 22,500 visitors along the South Rim at any one time; but the exact number will depend on the results of the monitoring program.

It is important to note that if the transportation and other facility changes proposed in this plan are not put in place, then the limit on the number of people who can visit the South Rim at any one time will be significantly reduced. Also, if visitation substantially exceeds forecasts, or if crucial transportation and other changes are significantly delayed, then that limit will need to be imposed much sooner. In fact, if the proposed changes cannot be put in place, day visitor limits and a reservation system will have to be imposed (see the description of alternative 1 in the Draft General Management Plan / Environmental Impact Statement).

\section{ACCESS / TRANSPORTATION}

\section{- Regional Access}

The Park Service will encourage alternatives to private automobile travel to Grand Canyon. These alternatives should complement the transportation and orientation proposals. Current examples include the Grand Canyon Railway from Williams, Nava-Hopi Tours from Flagstaff, and various shuttles from Tusayan and the Grand Canyon Airport in Tusayan. Additional alternatives in the future, besides the shuttle from the gateway information center in Tusayan, could include a canyon area shuttle service from a staging area in Valle, or proposals stemming from a regional 
transportation plan currently being developed under the auspices of the Arizona Department of Transportation.

North of Tusayan, at a site to be determined in cooperation with the U.S. Forest Service, a large parking facility will be constructed. It will be closely associated with the gateway information center (see page 37) and will be the starting point for various alternatives to automobile travel into the park, as described below.

- A bicycle/pedestrian trail will connect this facility with Mather Point and a network of similar trails along the South Rim.

- A rail shuttle between Tusayan and the Maswik Transportation Center, pending further environmental review, could be relocated from the airport to this north Tusayan site and provide transportation service into the park for up to $20 \%$ of park visitors. The Maswik Transportation Center would be the northern terminus for this shuttle route because the railroad track and the Maswik facility already exist. It is estimated that only up to $20 \%$ of visitors would use this service for the following reasons: (1) the landscape and other constraints, as well as the need to quickly distribute visitors, do not allow a larger facility at Maswik, (2) orientation provided at the Maswik facility would be less comprehensive than at the Mather Point orientation center, and (3) access from Maswik to the rim is less direct than from the Mather Point site.

- A shuttle service to the Mather Point orientation center will be provided for the remaining day visitors who do not use the trail or the train. This shuttle could use either rubber-tired buses on the existing road or a fixed guideway system (e.g., rail, light rail, monorail); such a system would likely be privately financed and operated if economically feasible and costs for riders disturbances, and (2) visitors must be well served by the routing. Existing disturbed corridors will be evaluated, including the original entrance road alignment (just west of the existing south entrance road) and the utility where reasonable.

Alternative analyses for providing these transit services will fully evaluate site-specific planning, design, and environmental factors. Two primary criteria will be used in selecting transit corridors (in addition to the required environmental review): (1) existing disturbed areas will be favored over new powerline corridor leading to Grand Canyon Village.

The capacity of the Tusayan parking facility is estimated at a maximum of 2,600 vehicles by the year 2010. If other mass transit options are effective at reducing the number of cars arriving at the park's gate - such as buses from Flagstaff, the train from Williams, or other options to be developed - the size of the lot may be reduced.

USFS Road 302/307 will remain unchanged as a dirt/gravel road, assuming that visitation estimates are correct and that funding is obtained for the major transportation system components. If these conditions cannot be met, the discussion of paving USFS 302/307 (in part or in whole) as an alternative to the park's East Rim Drive may be reopened. The possibility of straightening Rowe Well Road to avoid some of the rail crossings could be considered, but neither this road nor USFS Road 328 will be paved or graveled.

\section{- Roads, Parking, and Transit}

Overview: South Rim roads will be resurfaced, minor parking lot redesigns and improvements will be undertaken, and trails will be added in conjunction with road improvements.

Transit service, biking, and hiking will be the primary means for park visitors and residents to travel year-round along the South Rim. A convenient, attractive, and energy-efficient transit system will serve the developed areas from Hermits Rest to Yaki Point and from Desert View to the Tusayan Museum. Each bus will have a bike rack. Automobiles will be restricted from Hermits Rest 
to Yaki Point year-round by 2010. Grand Canyon Village will only be accessible by transit, hiking, or biking.

Grand Canyon Village Area: The Mather Point orientation/transit center will be the central transit center for the South Rim. This will be the primary point for visitors to make direct transit connections to the village and West Rim Drive, the Yaki Point trailhead, or the gateway information center in Tusayan. This center will include a transit pick-up/drop-off area, covered shelter and seating, information and display panels, and restrooms. Transit routes along the South Rim, with different bus sizes and schedules, will provide convenient visitor access to South Rim areas.

A well-screened, heavily landscaped parking area for up to 1,225 private vehicles (including RVs) and 60 tour buses will be constructed back from the rim at Mather Point. Visitors will have to walk a short distance (up to 1,000 feet) from the parking lot, past the orientation/transit center, to get to the rim, or they will be able to board transit or tour buses at this location to all South Rim destinations. Walking trails and bike paths (and bike rentals) will also be available. The parking area has been sized to allow a limited number of visitors to drive to within walking distance of the rim all year long, while still making an eight- or nine-month shuttle season from Tusayan viable. Visitors who cannot park at Mather Point because the lot is full will have to use alternative means of transportation to visit the park.

The parking area near Mather Point is scheduled to be built in two phases and will not be larger in capacity than 1,225 cars. If other transportation means are effective in reducing the number of cars arriving at the park (buses from Flagstaff, the train from Williams, or others that may be developed), the size of the parking lot may be reduced, making the second phase unnecessary. It is important to note that when this parking area is built and vehicle restrictions in Grand Canyon Village put in place, there will be an overflow parking demand. This overflow will not be accommodated inside the park. If the proposed parking area north of Tusayan is not in place at that time or the proposed shuttles are not available, other options through private entrepreneurs will be the only means for handling this overflow.

The South Rim entrance road from Mather Point to the village loop drive will be restricted to public transit vehicles only. Overnight private tour buses dropping passengers off at lodges along the rim will be able to use this portion of road only to drop off and pick up guests staying in lodges along the rim. If this additional use causes problems, then overnight tour buses will be directed to park at the Maswik Transportation Center, and shuttle service will be provided to rim lodging.

Day tour buses will be allowed to drive directly to the Mather Point orientation center, where they can park. The parking area at the Maswik Transportation Center will provide both day and overnight bus parking.

Local bus companies that demonstrate and maintain a good record of performance in the park, that operate clean-burning fleets, and that obtain training for drivers or guides from park interpreters may be provided broader access (at the discretion of the superintendent).

Hikers will continue to be permitted to park at or near East Rim Drive trailheads, as they do currently. However, they may be required to obtain special parking permits. If such use becomes a problem because of volume, a transit/taxi service will be established for access to these trailheads. Long-term parking for hikers on the corridor trails or on the Hermit Trail will be provided at the Mather Point orientation/transit center. Transit connections will provide access to these trailheads, and telephones will be available for 24-hour taxi service back to the parking lot (at a reasonable price and response time). 
All overnight visitors will be given identification for their cars. These vehicles will have access to the same roads and parking lots as day users; however, overnight visitors will be allowed to park their vehicles at lodging away from the rim or at their campsites. Visitors staying on the rim will have to park at the Maswik Transportation Center and lodge area, with shuttle service to the rim. The Maswik Transportation Center will also serve as the in-park staging area for the railroad spur when that system becomes operational.

Mail delivery by the U.S. Postal Service will be encouraged to reduce daily resident traffic to and from the business center.

A few new road sections will be constructed so private vehicles will not have to use public transit routes from Mather Point to the village. The new road sections, which will be built on disturbed lands wherever possible, include

- a 0.4-mile access road to link the RV campground and the existing south entrance road

- a 1.4-mile road to connect the Maswik Transportation Center and Maswik Lodge to Center Road

- a 0.25-mile section of road back from the rim to provide access to the Mather Point orientation/transit center (the existing road section closer to the rim will be converted to a bike path)

- a 0.4-mile link connecting residential areas to the business center

West Rim Drive will be converted to year-round public transit service only. The Maricopa Point overlook and parking area will be removed due to the proximity of a rare plant population, and the Hopi Point overlook will be redesigned for bike/pedestrian use only.

East Rim Drive: Through-traffic on East Rim Drive will not be restricted. However, developed overlooks and the Tusayan Museum will only be available for transit and tour bus vehicles during the peak use season. Automobiles will have access to picnic areas and roadside pulloffs - rock walls along the roadsides east and west of these pulloffs will discourage overflow parking. During the off-season, or until visitation levels dictate year-round restrictions, automobiles will have access to all East Rim overlooks and the Tusayan Museum.

Buses on East Rim Drive will operate as described below:

- All buses will be allowed access to East Rim Drive.

- About half of the existing developed areas on East Rim Drive will be designated for use by buses only. The other areas will be designated for private vehicles only (no buses).

- Desert View will be accessible to both buses and private vehicles.

- During the off-peak season buses and private vehicles will share access to all developed areas on the East Rim, as long as the off-peak season demand does not exceed the available parking supply at these developed areas.

Desert View: A bypass will be constructed on Arizona 64 around Desert View to eliminate traffic traveling through the developed area. The present road into Desert View will be changed to a spur road on the east and a bike trail on the west. Portions of the spur road will be realigned to improve safety and so that it functions effectively in conjunction with the proposed bypass.

A new entrance station for Desert View, with at least two entry lanes, will be developed east of Desert View. The existing entrance station will be removed and the area revegetated.

The Desert View orientation/transit center will be the transportation hub of the East Rim. Visitors will be able to park their cars and board transit or tour buses to all South Rim destinations. Alternatively, visitors will be able to rent bicycles and use the bike paths or pedestrian trails along the rim in both directions from Desert View. The transit center will include transit pick-up/drop-off areas, a covered seating and waiting area, and information panels. Restrooms will be provided in the orientation center nearby. Buses will be fitted with bike racks. 
The parking lot will accommodate 450 private vehicles (including RVs) and 15 buses, which is sized to accommodate projected demand to the year 2010. It will be constructed in the existing concessioner housing area. This parking will be adjacent to the Desert View orientation/transit center and will be a short walk (up to 1,000 feet) from the rim. Access to the lot will be from the south to keep traffic noise as far from the rim as possible.

Shuttle service from Desert View to the Tusayan Museum will be available, and tours will take visitors from Desert View to destinations along East Rim Drive and to the Mather Point orientation/transit center.

Off-Season Roads, Parking, and Transit: Public transit service will be adjusted during offseasons in terms of schedules, numbers of buses, routes, and bus types to meet different use patterns. However, by the year 2010 visitor use is projected to increase to such levels that the entire area from Yaki Point to Hermits Rest, including major portions of Grand Canyon Village, will only be accessible by transit or hiking/biking year-round. Many parking lots within these areas will then be removed and revegetated, while public transit access roads and parking spaces for service vehicles will be retained.

During the off-season visitors in private cars will initially be allowed access to overlooks along East Rim Drive that are accessible only by bus during the high use season. As visitor use increases, however, bus access to these overlooks will be gradually extended until year-round service is offered by 2010; at the same time private vehicle parking lots will be redesigned for bus use only, and portions of each lot will be revegetated. At that time private vehicles will only have access to pulloffs along the rim and picnic areas.

Employee Roads, Parking, and Transit: An efficient employee shuttle system will be developed for NPS and concession employees residing both in the park and in Tusayan. Employees will be encouraged to use alternate transportation modes.

The parking area at the existing visitor center/NPS headquarters will be designated for employees and NPS vehicles only (this building will be used as the NPS central administration building). This centralized parking facility will provide employee parking in the village; no new parking will be developed for employees. Employees will be directed to use roads back from the rim and to stay off public transit routes except for special work-related situations.

\section{- Trails}

Outside the Park: The National Park Service will work with other agencies to extend the Arizona Trail, linking the South and North Rims to Flagstaff and areas farther south, as well as to the north.

Hundreds of miles of unmaintained trails and roads for hiking, horseback riding, and biking in the Tusayan ranger district of Kaibab National Forest will remain easily accessible to South Rim visitors. The Grandview Lookout/Hull cabin area will continue to have groomed trails for crosscountry skiing, and outfitters for biking and horseback riding operating just outside the park will still have their own sections of maintained trails. Horseback rides to the rim edge will remain available. The U.S. Forest Service will continue to expand its trail system and encourage nonmotorized use.

South Rim and Desert View: The Arizona Trail will be completed as an unpaved trail from Grand Canyon Village to USFS lands to the southeast. It will be used for hiking, biking, and horseback riding, consistent with the park's Backcountry Management Plan.

Bikes will still be allowed on all roads. An off-road bike trail system will be provided to link Hermits Rest and Desert View. The trail will be used by both bikers and pedestrians except in very heavy use areas, such as between the business center and the village, where separate trails will be 
provided. The trail system will generally be north of the road on the East and West Rims so as to avoid road-crossing conflicts, and disturbed areas will be used whenever possible to limit resource impacts. Bike trails will also be provided in the park's residential area to link the community to all major use areas and the primary bike system. A bikeway plan will determine more exact routes, paved and unpaved sections, bike/pedestrian overlooks, and other design details. Bike rentals will be offered in all major use areas, along with secure bike racks.

Road sections that are no longer needed for motorized vehicles at Mather Point, Desert View, and the Hopi Point overlook, plus the village loop bypass, will all be converted to bike paths. A few overlooks along the East Rim will be added for bike and pedestrian access only.

Pedestrian trails along the rim will be substantially expanded. Care will be taken to avoid archeological sites and ethnographic resources and to minimize tree removal and disturbance to other vegetation. The following trails will be extended or improved:

- an improved trail from Yaki Point to Verkamp's

- a loop trail from the Grandview overlook eastward to the Coconino Rim (incorporating the Grandview road)

- a trail from Desert View to the Tusayan Museum along the rim, plus trails in conjunction with the proposed outdoor exhibits in the museum area

- a trail (along an old road alignment) from Desert View to Cape Solitude

- a trail from the Tusayan orientation/transit center to the Mather Point orientation/transit center

\section{THE Visitor EXPERIENCE ALONg THE RIM}

The plan will preserve the wilderness threshold of the visitor experience along the rim of the canyon, and proposed actions will ensure enjoyable experiences as visitors arrive at the rim. The anticipation and sense of arrival for first-time visitors as well as returning visitors are key elements in the visitor experience, and they will be maintained.

The visitor experience at the Grand Canyon can be described as basically unfolding in two phases. The first phase is the sense of arrival and viewing the canyon, and all visitors participate in this experience. The second phase is exploring the canyon below the rim. Even though thousands of people every year hike or ride the corridor trails into the depths of the canyon, and thousands more float the river, the majority of visitors do not have the time or inclination to do this, and for them taking in the spectacular vistas from the rim constitutes their park experience.

The intent of the plan is just as much about preserving nature and wildness in the Grand Canyon as about protecting the visitor's experience of wonder and awe when first gazing into the depths of the canyon. In one sense the visitor experience at the Grand Canyon depends on the park staying wild below the overlooks and staying quiet and uncrowded behind them. The plan will protect and ensure the individual visitor's opportunity to experience that awe-inspiring first look into the Grand Canyon from along the rim, and it will maintain the opportunity for threshold wilderness experiences along the many miles of rim and corridor trails.

\section{FUtURe ENVIRONMENTAL ANaLYSes}

A general management plan is primarily a conceptual plan. Therefore, in most cases additional site-specific planning and comprehensive design, accompanied by analyses of environmental 
impacts, will have to be completed before any proposed actions are implemented. Future actions will be undertaken in full compliance with all applicable laws, policies, and memoranda of agreement.

\section{ORIENTATION AND INTERPRETATION}

\section{- Regional Information}

The National Park Service will work actively with area partners to ensure that visitors receive adequate and appropriate information to plan their trips before they reach the park. Partners in this cooperative effort may include the Flagstaff Chamber of Commerce at the Flagstaff visitor center, the Kaibab National Forest and the city of Williams at the Williams visitor center, the Cameron Chapter of the Navajo Nation in Cameron, the Kaibab National Forest at the Kaibab Plateau visitor center, and the city of Kanab at the information center in Kanab. Regional planning will also be conducted to coordinate efforts to manage resources and visitor use, and to help ensure appropriate sustainable development.

Information will be provided to potential visitors before they leave their homes through media such as video, telecommunications, and Internet, as well as mailings. This information will help visitors understand the need to plan their trips well ahead and will help them formulate realistic expectations.

When visitors are on their way and as they come closer to the park, more detailed information will be provided. For example, airports that serve Grand Canyon visitors may have interactive computer installations, while visitor centers within 90 minutes of the park will have an informed person with whom visitors may speak. Each information center will probably require a different level of support from the Park Service, including facility funding, staffing, training, and frequent information updates. When reservations are required for day visits, as is proposed for the North Rim in a few years, visitors will be able to make these reservations at visitor centers in gateway communities, as well as many other off-site locations.

The Park Service will encourage the state of Arizona to include Grand Canyon information at interstate rest stops and welcome centers.

\section{- Tusayan Gateway Information Center}

A gateway information center will be provided north of Tusayan, which is the preferred site in order to reduce the length of the transit route and to enhance the sense of arrival for visitors. The center will provide regional trip-planning information, as well as restrooms, telephones, an outside information kiosk, day parking, and transit service to the park. Other possible functions include

- lodging/campground check-in for the national park, the national forest, and possibly Tusayan, along with information on regional accommodations and a phone bank for making lodging reservations

- sales of park entry passes, NPS backcountry information, and a direct phone link to the backcountry office

- limited local area theme exhibits and book sales

- offices related to the operation of the building

- USFS administrative offices and services

- bike rentals 
The facility may be jointly funded and operated by the Forest Service and the Park Service, or private entities may also be involved.

\section{- South Rim Overview}

Two visitor orientation centers will be developed - a primary center near Mather Point and a smaller one at Desert View. These centers will help visitors to understand and appreciate the park's major interpretive themes and to plan their visits. The Maswik Transportation Center will continue as a minor orientation center.

New wayside exhibits, as proposed in the wayside exhibit plan, will be provided along the rim, and an outdoor exhibit will be provided at the Yavapai Observation Station. Interpretive exhibits focused on particular themes will be provided at the existing powerhouse area in Grand Canyon Village, the Yavapai Observation Station, and the Tusayan Museum.

Traditional and contemporary relationships of American Indians to the Grand Canyon and their use of its resources will be interpreted in appropriate places throughout the park. This interpretation will include, but not be limited to, cultural demonstrations by American Indians. The program will be based on formal partnerships modeled after those that currently exist between the National Park Service and American Indian groups.

Hermits Rest, Lookout Studio, and the Desert View Watchtower (all national landmarks designed by Mary Jane Colter) will be converted back to their original uses, and the gift shops will be reduced in size. Limited exhibits about the history of the individual structures and their surroundings may be provided.

Kolb Studio will be converted into a museum/interpretive/office facility; and a restroom will be provided in the garage.

Book sales by the park's cooperating association will be provided in all the orientation centers and at major interpretive facilities. Sale items at the interpretive facilities will be directly related to the themes presented at that site, with the primary sales facilities at Kolb Studio and the Mather Point orientation/transit center.

At Orphan Mine hazardous materials will be removed and the area revegetated. The mine will be interpreted through wayside exhibits, personal service programs, and possibly as part of one of the educational exhibits in the powerhouse area. The headframe at the Orphan Mine will be removed, and any opening easily accessible to visitors will be sealed. These actions will be implemented in compliance with the provisions of federal historic preservation laws and NPS Management Policies and will be undertaken after further consultation with the Arizona state historic preservation officer under the terms of the August 1995 programmatic agreement between Grand Canyon National Park, the Arizona state historic preservation officer, and the Advisory Council on Historic Preservation.

\section{- Grand Canyon Village Area}

Mather Point: The Mather Point orientation/transit center will be the main point for visitors on the South Rim to learn what there is to do at the Grand Canyon. The center will be set back approximately 400-600 feet from the rim at Mather Point. Several pedestrian paths will provide easy access to the point.

The facility will be designed so visitors can be oriented quickly, choose the options they desire, and spend more of their time experiencing the park. Answers to the most frequently asked questions will be readily available so visitors will not have to wait in lines for basic information; this will allow more time for visitors to get answers about specific situations. 
Facilities at the orientation center will include

- an outdoor plaza, with seating and landscaping; a 24-hour lodging information kiosk; restrooms; and a phone

- a parkwide information desk, exhibits to introduce visitors to all educational themes represented in the park, and cooperating association book sales (no gift shops)

- a backcountry permitting station and safety video area, and offices directly related to services at this center

- lodging information phones (registration will be at the gateway information center or at the lodge front desks); concession tour registration (mule rides and tour buses); and bike rentals

Grand Canyon Village: Interpretive facilities will be concentrated in the powerhouse area of the historic village. This entire area will be for pedestrians only and will be directly linked to the facilities on the rim across the railroad tracks. These interpretive facilities will be housed in historic structures that will be rehabilitated. Food service will also be provided. With the space available, the following interpretive functions may be accommodated (specific interpretive uses will be decided during subsequent design work):

- an education center in the former powerhouse, where a wide range of themes and hands-on exhibits will be offered

- a children's museum or artists-in-the-park facility in the former horse barn

- an American Indian cultural center in the former mule barn

- a multi-media education center in the former community building

- visitor services in the remaining buildings

Kolb Studio will be converted to interpretive space. The Fred Harvey exhibit in Bright Angel Lodge will be updated, and the space will be redesigned to provide a comfortable lounge area to relieve the existing overcrowded lounge. An amphitheater, waysides or brochures, and personal service programs will also be provided in the historic village area.

Business Center: The existing visitor center amphitheater will be relocated to a nearby area central to lodging and camping facilities.

\section{- Yavapai Observation Station and Tusayan Museum}

Interpretive exhibits at the Yavapai Observation Station and Tusayan Museum will be simplified to focus on only selected themes, and related outdoor exhibits will be expanded. The Yavapai Observation Station will primarily be used for viewing the canyon, with a few exhibits on geology, physiography, and related topics. The Tusayan Museum exhibits will focus on prehistory. Only a small area of each building will be used for theme-related sales by the cooperating association.

\section{- Desert View}

The visitor experience at Desert View will be improved by moving most visitor services farther back from the rim, by keeping the rim open for viewing, picnicking, and enjoying the Watchtower, and by restoring the tower to its original use and providing a few interpretive exhibits. Exhibits will relate to American Indian culture and the cooperative effort between Mary Jane Colter and the Hopi Indians to build the tower and paint the inside.

For visitor orientation, a small, simple building will be constructed on the east side of the existing parking area so as to minimize any visual obstructions of the Watchtower and to keep the rim as the primary focus for visitors. This facility will provide 
- general trip-planning and transit information, small-scale exhibits emphasizing American Indian themes and also introducing all other Grand Canyon themes, and cooperating association book sales

- phones for lodging and backcountry use reservations

- restrooms, and a 24-hour information kiosk and phones

\section{VISITOR SERVICES}

\section{- Outside the Park}

Visitor services related to the Grand Canyon (primarily lodging, camping, restaurants, and gift shops) will continue to be available in areas an hour or more away from the park and in Tusayan.

\section{- South Rim}

Visitor services on the South Rim will be concentrated in the historic village, the adjacent powerhouse area, and the business center. Functions now occurring in these areas not directly related to visitor services (for example, maintenance, storage, and employee housing) will be moved to areas where the visitor experience will not be affected. Instead of building new facilities, historic structures will be adaptively reused for visitor service functions.

The number and scale of gift shops on the rim will be reduced, and sales items will be changed to reflect the type of items that were historically sold there or that are related to themes interpreted in the park. The powerhouse area will become a major visitor use area, with a mix of interpretive and visitor service facilities. Some lodging will be moved from the village to the Yavapai Lodge area off the rim. Existing business center uses will be retained.

Hermits Rest, Lookout Studio, and the Desert View Watchtower (all designed by Mary Jane Colter) will be converted back to their original uses and characteristics. Hermits Rest will once again be a rest area with a small gift shop and limited food service in spaces that were historically used that way. Lookout Studio will focus on art, primarily regional area paintings, photography, posters, post cards, and other art-related items, and a seating and rest area will be provided. The Desert View Watchtower will be used as it was historically - an area for people to rest, talk, view the canyon, and have a beverage and snack; only the original backroom space will be used for gift sales.

Numerous restrooms will be added along the South Rim, particularly at all major parking/staging areas and orientation centers, all food service and interpretive facilities in the village, the Bright Angel trailhead (at the Kolb Studio garage), the South Kaibab trailhead, Yaki Point, and the Tusayan Museum. In high use areas where water is not available, water-conserving toilets will be added. This type of toilet will replace facilities at Hermits Rest and could be added near the Hopi, Grandview, and Lipan overlooks.

Restrooms in the Bright Angel Lodge will be expanded into the hair salon space. Current facilities at El Tovar, the Arizona Steakhouse, and the depot will remain.

Village Lodging and Camping: Approximately 240 rooms will be added, for a total of about 1,160 rooms. Visitor lodging will continue at El Tovar and Bright Angel. The Kachina and Thunderbird Lodges will be removed from the rim ( \pm 100 rooms), and approximately 100 replacement rooms will be provided at Yavapai West, where the existing 160 units will be replaced by approximately 260 new units. The Victor, Victor annex, and Colter employee dormitories will be 
converted to lower priced visitor lodging ( \pm 155 rooms total). These facilities will be designed like many European lodges, with a central lounge and shared restrooms.

The Rouzer and Brandt dormitories in the business center area will also be converted to lodging accommodations for special groups, such as Grand Canyon Field Institute students, artists-in-thepark, Elderhostel visitors, and scout troops. When not rented by recognized groups, the space will be available to the public as lower priced lodging.

The Maswik historic cabins $( \pm 30)$, now used by employees, will be converted to visitor lodging. The Maswik plywood cabins $( \pm 10)$ will be removed and that area revegetated.

Mather campground (326 spaces) will be retained. Camper services (laundry, showers, restrooms) will be renovated and enlarged. The RV campground will be redesigned to provide about 110 spaces (currently about 80).

Village Food Service, Shopping, and Other Facilities: Food service capacity will be increased. The restaurant at El Tovar, the Arizona Steakhouse, and the Yavapai cafeteria will remain. The Bright Angel Lodge will be remodeled and will continue to provide food service, restrooms, and gift shop space; the gift shop may be reduced in size. The Maswik cafeteria will be converted to table service during the evenings. The Verkamp's, El Tovar, and Yavapai Lodge gift shops will remain.

Once the Kachina and Thunderbird Lodges have been removed, this area will be used for program space, American Indian cultural celebrations, and outdoor seating. The design will be plaza-like and will visually connect the Bright Angel, rim, and El Tovar. The landscape design will keep with the rim's cultural landscape.

Outdoor seating and gathering space will also be provided in the powerhouse area and will be designed to keep with the character of the cultural landscape. Visitor services that may be provided in this area include the following (the blacksmith shop will remain as it is):

- a restaurant in the historic laundry building (fast-food/take-out service for breakfast and lunch, table service for dinner)

- bike rental in the Grand Canyon National Park Lodges maintenance building

- ATM and post office in the magistrate's office

- a corner store, with groceries, supplies, and a deli to replace the recreation center that burned

Once the gravel parking lot has been removed from the historic depot area, the switches and tracks will be restored. Rail cars for food service or overnight accommodations may be considered as uses for these tracks.

Existing services at the business center will continue, including the grocery/deli/supply store, post office, bank, and Yavapai gift shop and cafeteria.

\section{- Desert View}

Services at Desert View will be moved back from the rim to provide more space for visitors to enjoy the views and to rest and relax. The Watchtower, which will primarily be a rest and interpretive area, will offer very limited food and drink service and a small gift shop. The restroom facility will be removed and replaced as part of the Desert View orientation center.

The Grand Canyon National Park Lodge's trading post will be moved southeast of Babbitt's store, either to the existing parking lot or to adjacent disturbed areas. The existing contact station will be used for park operations or for visitor services. The 50-site campground will be increased to 100 sites in the area where campground utilities already exist.

A small house north of the gas station will be adaptively reused as a bike rental shop. The gas station will remain. 


\section{CoOperation OUTSide Park Boundaries}

The National Park Service will consult and cooperate with its neighbors with regard to activities occurring outside park boundaries that may affect park management practices.

The Park Service will continue to support Kaibab National Forest in implementing the forest plan and expanding recreational opportunities in the Tusayan ranger district when those activities are compatible with this plan.

The Park Service, as a cooperating agency on the Tusayan land exchange, will continue to support Kaibab National Forest in that agency's efforts to consolidate inholdings in the Tusayan ranger district and to provide lands for coordinated community development, compatible with park purposes, in the Tusayan area. If the exchange is not completed, or if the selected lands are in an inappropriate location for park support facilities, then the Park Service will continue to work with the Forest Service to place some park support facilities on forest lands.

\section{Sustainable DeVelopment}

Sustainable development attempts to minimize human impacts on the earth, recognizing that development practices often deplete natural support systems, or may lead to the destruction of critical cultural resources. Central to the concept of sustainable development is the idea that all decisions - from initial concept, through design, construction, and operation - must be evaluated in light of principles for natural and cultural resource conservation.

The Park Service will promote environmentally sensitive planning and design and will demonstrate technologies and practices that reduce environmental impacts and produce benefits in energy conservation, solid waste management, transportation, water conservation and reclamation, wastewater treatment, and community organization.

\section{AREa Operations}

All South Rim jobs that do not require a frequent or direct relationship to park resources, facilities, or visitors will be moved to Flagstaff or Williams, where housing and office space are more readily available. At a minimum, this will mean $3 \%$ of the current South Rim workforce. Relocation goals will be $20 \%$ of the current summer NPS South Rim staff and 5\% of the current summer Grand Canyon National Park Lodges (GCNPL) staff.

Replacement units for substandard housing and additional required housing will be provided either in heavily disturbed areas in Grand Canyon Village and Desert View (where utilities already exist) or adjacent to Tusayan outside the park.

The locations of most management support operations for both the Park Service and its cooperators will change, and in nearly every case additional space will be provided. When determining specific locations for management support functions, the following will be considered: health and safety needs, visitor experience, the square footage of buildings and disturbed lands, what functions need to be near each other for efficient operations, and future needs. Management support functions remaining in the park will be accommodated by adaptively reusing existing structures and using previously disturbed lands for new structures wherever possible. 


\section{OUtSide the Park}

\section{- Housing}

Positions moved out of the park will no longer need employer-provided housing. Up to 500 housing units that are needed near the park but that cannot be accommodated inside the park within the designated disturbed areas will be provided adjacent to Tusayan. There will be a range of housing types and densities. The Park Service prefers that these units be provided within the community of Tusayan. If this need cannot be met by private enterprise, then a joint NPS/USFS federal housing area will be built nearby on forest land.

\section{- Community Services}

This plan proposes that a major center for community services be gradually created in Tusayan, with facilities being provided over time as the needs are identified. Areas for community services may be provided either as part of a proposed land exchange by the Forest Service, as part of a federal housing area on forest land if the land exchange does not occur, or within Tusayan. Community facilities needed may include the following:

- additional school facilities (no expansion within the park), churches, and a medical facility

- a recreation center, meeting rooms, a day-care facility, and a theater

- a neighborhood and community park, with ballfields, playground, picnic/seating areas, and other typical neighborhood and community park amenities

- a laundry, an oversized vehicle storage area, an auto repair center, and a grocery/supplies store

\section{- Utilities}

The National Park Service will work cooperatively with the U.S. Forest Service, the landowner involved in a proposed land exchange (see page 61), and other entities from the town of Tusayan to provide adequate water specifically for the gateway information center and a federal housing area. The gateway information center and the federal housing area will tie into existing or proposed utilities for wastewater treatment, and the Park Service will expand utilities if necessary.

\section{Grand Canyon Village}

\section{- Housing}

Up to 500 housing units will be provided within the park in disturbed areas to replace some 115 substandard housing units, to reduce overcrowding, and to meet additional NPS and concessioner housing needs. Substandard housing units will be rehabilitated, replaced, or removed. Housing will include all dorms needed for park operations by the year 2010 and high-density housing (with an overall density of 15 dwelling units per acre). Housing will be built on existing disturbed lands in two parcels - Pinyon Park and the former YACC camp area; no undisturbed lands will be used for housing. 


\section{- Community Services}

Grand Canyon Village will continue to provide community services for the in-park community (including the existing school, day care, grocery store, and clinic). Any needed expansion of these functions will occur outside the park, and any addition of services within the park will be accommodated by first considering the adaptive reuse of historic structures. All services except Babbitt's store are planned with very limited parking. Residents will be encouraged to use the employee or visitor shuttle or other alternative transportation modes. The historic NPS maintenance facility will be converted to recreational space for residents. A new recreation center to replace the one that burned will be built adjacent to the Grand Canyon School campus.

The post office, bank, and Babbitt's store will remain in the business center for use by visitors and residents. To provide better mail service and to reduce business center traffic, centralized mailboxes will be provided throughout the community.

\section{- NPS Management Support Functions}

Except for the Albright Training Center, all NPS operation spaces will change at least slightly. The existing visitor center/headquarters building will be used entirely as the park's administrative headquarters. The building will be remodeled, and an addition may be built if the atrium cannot be used for office space.

The backcountry office and some interpretive offices will be moved to the Mather Point orientation/transit center, and the existing backcountry building and a portion of the parking area will be removed and the area revegetated. Expanded office space for the concessioner will be provided in the existing public garage at the general office building. A new fire and safety building for the Park Service and Grand Canyon National Park Lodges will be built in the disturbed area at the existing NPS maintenance facility.

NPS maintenance operations, warehouses, and Denver Service Center construction offices will be consolidated and moved to an area immediately east of the existing helibase. The site will incorporate the proposed transit operations, occupying all of the land used by the existing transit operations and expanding into undisturbed forested areas surrounding the existing dry dump. Employees will be able to store their RVs and boats at the dry dump. The Southgate disturbed area will be used for maintenance material storage, for NPS mules and horses, and for the storage of RVs and other items. All conflicting uses within the flight safety zones of the helibase operations will be removed, and the helibase will continue to operate in its existing location.

The boat shop will be moved to Lees Ferry, subject to amendment of the 1985 Lees Ferry Development Concept Plan (prepared by the Glen Canyon National Recreation Area).

\section{- Other Management Support Functions}

Most management support functions will be moved so that the powerhouse area can be used for interpretation and visitor services and so that adequate space can be provided for future concessioner operations. A few existing buildings and spaces will remain for concessioners, as indicated below, although uses may change:

- the NPS maintenance complex for GCNPL maintenance

- the NPS warehouse for GCNPL commissary, purchasing, retail storage

- the general offices (public garage end included) for GCNPL personnel, uniform center, housing director, food and beverage director

- the old schoolhouse for training director and training room

- a new barn and corral on the west edge of the village for the mule operation 
- the dry storage area for transportation dispatch, maintenance, and parking

- the old superintendent's house remains GCNPL administrative offices

- the personnel building to be removed

\section{- Utilities}

Grand Canyon National Park will explore alternative water sources to the current use of Roaring Springs and the transcanyon waterline. If an alternative source can be found that would have a reduced impact on park resources, it will be investigated and used if financially feasible. If such a source cannot be found, the transcanyon waterline will be rehabilitated and reengineered to return water that is not pumped to the rim back to Roaring Springs Creek rather than overflowing into Garden Creek as currently happens. If Roaring Springs is retained as the South Rim water source, water consumption (measured in gallons per visitor pumped to the rim) will be reduced from the current 43 gallons to 20 gallons by 2010 .

To achieve this goal, water conservation measures such as the use of low-flow fixtures in new and existing facilities, the expanded use of reclaimed water, and perhaps some precipitation harvesting will be employed. Without these measures an additional 5 million gallons in storage capacity and longer hours of water pumping would be required.

The wastewater treatment facility will remain the same, with connecting lines to the Mather Point orientation/transit center and to the proposed new NPS maintenance area at the current dry dump. The overflow lagoons at the South Rim treatment plant will be redesigned and reduced significantly in size since they are only needed for emergencies rather than daily use.

\section{DeSERT View}

\section{- Housing}

Approximately 70 housing units will be built to replace about 10 substandard units and to meet additional housing needs. This housing will be developed in a disturbed area southeast of Arizona Highway 64; any housing that does not fit within this heavily disturbed area will be tightly clustered in areas where utility extensions already exist. All housing will be removed from the GCNPL area just south of the existing parking lot, and this area will be converted to parking and a transit facility.

\section{- Community Services}

A new employee laundry and lounge will be built as part of the consolidated housing area. In addition, a small outdoor recreation space will be provided for picnicking and games.

\section{- Management Support Functions}

Existing management support facilities will be retained except for the construction of a new maintenance building for Grand Canyon National Park Lodges and a new NPS ranger operations and maintenance facility. These facilities will be located in disturbed areas currently occupied by substandard management support facilities or housing. 


\section{- Utilities}

The wastewater treatment system at Desert View will be upgraded. Beyond the search to reduce water use impacts in the park, only minor improvements for water will be made, such as upgrading pressure pumps. The existing lagoons will be improved, and low-flow fixtures will be added to the facilities.

\section{Other Areas and CoOperators}

All housing except the historic residence at Hermits Rest will be removed, and housing will either be provided in the village or adjacent to Tusayan outside the park. Existing housing at the South Kaibab trailhead will be rehabilitated.

The Babbitt's store offices will remain at the business center, and the existing NPS and GCNPL mule barns will remain at the South Kaibab trailhead. 


\section{SUMMARY OF NORTH RIM ACTIONS}

The vision for the North Rim is to provide a low-key, uncrowded atmosphere that offers visitors opportunities to be intimately involved with the environment.

To achieve this vision, a day visitor reservation system will be implemented, visitor use will be better distributed on Bright Angel Point, and a greater percentage of people will be encouraged to visit Walhalla Plateau. Private vehicle access on Bright Angel Point will be restricted, and transit service, as well as bike and pedestrian pathways, will be expanded on the point and Walhalla Plateau.

Visitors will receive information about visiting the North Rim outside the park at the U.S. Forest Service's Kaibab Plateau visitor center at Jacob Lake and at an orientation center on Bright Angel Point at CC Hill. Lodging opportunities will be increased by about $25 \%$ by adaptively reusing existing structures, while a few campsites may be removed as part of a redesign of the campground.

\section{NORTh Rim PlanNing ISSUES}

\section{- Region}

Visitor information and regional orientation before visitors reach the park is inadequate.

There are no coordinated means to work with outside entities to address development needs and environmental concerns.

\section{- Visitor Experience}

Many visitors favor the current low-key experience, but there is concern that this experience could be lost with more visitation.

Aircraft noise intrudes on the experience in several areas.

Traffic flow is poor, and signs are confusing in particular areas.

There is not enough parking on Bright Angel Point.

Orientation and information services are inadequate.

Food services are overcrowded and lack diversity.

Access to Cape Royal is by way of a steep, narrow, windy road.

There is a question about opening Bright Angel Point to additional types of winter use.

\section{- Cultural and Natural Resources}

Archeological sites are being vandalized, especially in the backcountry.

Fuel loads in wooded areas should be more efficiently reduced.

\section{- Utilities}

There are too few restrooms in the lodge area; restrooms are lacking in other areas. 
The capacity of existing septic, sewage, and water systems may not be able to accommodate future growth.

\section{HOW VisitoRs ARRIVE ON THE NORTH RIM}

- Visitors will receive information packets at home that describe transportation alternatives, visitor services, lodging, etc. They will receive day use permits by mail.

- Visitors may stop at regional gateway information centers at Las Vegas, St. George, and Kanab/Fredonia to obtain information and day use permits.

- An electronic message sign near Jacob Lake will advise travelers about the need for day use permits.

- Visitors will be encouraged to stop at the gateway orientation center at Jacob Lake to obtain information and day use permits if they do not already have them.

- Visitors will stop at the park entrance station, where permits will be checked.

- Visitors may stop at the CC Hill orientation center. Day visitors seeking access to Bright Angel Point will park here and take the transit service to Grand Canyon Lodge.

- Private vehicles and buses less than $22^{\prime}$ in length will have access to scenic roads to Cape Royal and Point Imperial. All oversized vehicles will park at CC Hill.

- Overnight guests will proceed with their vehicles to the lodging area (overnight permits will be verified at a checkpoint station on the road to Bright Angel Point). Tour buses with overnight guests will also be allowed to drive to the lodge.

\section{VISITOR EXPERIENCE}

\section{Visitor Use Patterns}

The park expects to limit day visitor numbers on the North Rim sometime between 2005 and 2010, depending on how well visitors can be distributed throughout the developed area. These shifts in use patterns are expected to occur because of the following factors:

(1) More visitors will visit the Walhalla Plateau because (a) some visitors will prefer to drive their own vehicles, which will be allowed on the plateau, rather than using public transit, or hiking or biking, which will be required on Bright Angel Point; (b) visitors will be encouraged to visit the Walhalla Plateau and will be prepared before arriving at the park for that more limited experience; and (c) a convenient bus service will be made available to visitors to the plateau.

(2) Visitors who go to Bright Angel Point will be likely to stay longer at that location because of having to park their vehicles and use transit, or hike or bike; this could reduce the amount of time spent visiting Walhalla Plateau.

(3) Some visitors may decide to leave the park once they have viewed the canyon from the proposed North Rim orientation center on Bright Angel Point.

According to the "Grand Canyon North Rim Visitor Utilization Study" (Operations Research Consulting Associates 1993), a maximum of about 1,700 visitors at any one time can now be accommodated within the North Rim developed area. Based on an average four-hour stay, about 
430 visitors per hour can enter the park (a peak hourly rate of \pm 130 vehicles, multiplied by 3.3 visitors per vehicle). With a nominal shift in visitor use patterns, which could be accomplished by suggestions to visitors to slightly alter use patterns, approximately $28 \%$ more visitors than today could be accommodated (amounting to a maximum of 550 visitors per hour, or \pm 170 private vehicles, RVs, and tour buses). With a substantial shift in visitor use, 38\% more visitation could be accommodated (about 590 visitors per hour, or \pm 180 private vehicles). As on the South Rim, a monitoring system will be implemented to record resource damage and visitor use patterns so that the attendance limitations can be adjusted to reflect appropriate use once the plan is implemented.

\section{ACCESS / TRANSPORTATION}

\section{- Regional Access}

The communities of Kanab and Fredonia are strategically located to serve as tourist hubs for the "Grand Circle." Many tourists who want to visit the North Rim are also interested in seeing attractions such as Zion National Park, Bryce Canyon National Park, Glen Canyon National Recreation Area, Kodachrome Basin State Park, Coral Pink Sand Dunes State Park, Pipe Spring National Monument, and Tuweep. Visitors will be encouraged to stay in Kanab and Fredonia and to take day trips from these hub communities in order to help distribute visitors among the region's various scenic destinations.

The Park Service will work with regional entities to encourage visitors to use vehicles less than $22^{\prime}$ long when they visit the North Rim because of park restrictions on vehicle sizes. The Park Service will continue to support the Arizona Department of Transportation in maintaining Arizona Highway 67 between Jacob Lake and the park as a two-lane road that is closed and unplowed in the winter. The Park Service will also continue to support the U.S. Forest Service in managing this road corridor for its high-quality scenic resources.To help preserve the secluded and natural character of destinations inside the park on the North Rim, the Park Service will also work with regional entities to ensure that roads outside the park that provide access to nonwilderness road corridors in undeveloped areas remain unpaved and do not change in character.

\section{- Roads, Parking, and Transit}

A convenient, attractive, and energy-efficient transit system, which will be accessible to visitors with special needs, will be provided on Walhalla Plateau and Bright Angel Point. Visitors will be encouraged to use the transit system on Walhalla Plateau, and they will be required to use it, or hike or bike, on Bright Angel Point. Transit vehicles will be only about $22^{\prime}$ in length and will be equipped to carry bikes.

A small North Rim orientation center, staging area, and transit center will be developed on CC Hill. The access road will be realigned to reduce grades, and parking will be provided for approximately 400 vehicles ( 375 cars, 16 RVs, and 4 buses, requiring \pm 4 acres). In conjunction with this action, the parking lot at the North Kaibab trailhead will be removed and the area revegetated. The transit center will have a shelter, waiting area, information panels, and restrooms; from here visitors will have access to Bright Angel Point and all overlooks on Walhalla Plateau.

Day visitors on Bright Angel Point will have to use the transit system or hike or bike to their destinations. Overnight guests will receive a pass to drive to their lodging or campsite and park, and will then have to use the transit system. 
Vehicles on the entire Walhalla Plateau, from the Bright Angel Point/Walhalla Road intersection, will be limited to a maximum length of $22^{\prime}$ and width of $8^{\prime}$. Parking lots on the plateau will be sized for the carrying capacity established for each overlook. No parking lots will be reduced in size until after use patterns on the plateau become established (based on the changes made by this plan) and have been monitored. Parking pull-offs for just a few cars will be established at new trailheads.

Except for a few concessioner vehicle spaces, employee parking will not be provided at Grand Canyon Lodge. The concession employee shuttle will be retained, and an efficient NPS employee shuttle will be established (possibly a joint system for both NPS and concession employees).

\section{- Trails}

Outside the Park: Visitors will still have access to the Arizona Trail from north of Jacob Lake, through the park, and to the south. In addition, hundreds of miles of maintained and unmaintained roads and trails will continue to be available for hiking, horseback riding, and biking in the USFS North Kaibab ranger district.

Inside the Park: An unpaved section of the Arizona Trail will be completed to connect Kaibab National Forest to the North Kaibab Trail. The trail will be used for hiking, biking, and horseback riding, consistent with the park's Backcountry Management Plan.

Bike riders will continue to share the existing road system with motorized vehicles and will be allowed on the Point Sublime road. A bike trail (separated from the road wherever possible and constructed outside the proposed wilderness boundary) will be developed to link CC Hill, Bright Angel Point, and all overlooks on Walhalla Plateau. Disturbance to archeological sites, ethnographic resources, and natural resources will be minimized and mitigated.

A rim trail will be developed around Bright Angel Point to connect CC Hill, Grand Canyon Lodge, and the Transept Trail.

Approximately 10 miles of rim hiking trails will be constructed on the Walhalla Plateau to link Point Imperial and Vista Encantadora. Visitors will still be able to use abandoned fire roads within the proposed wilderness area for hiking.

A few short sections of mule trails will be constructed to connect the mule staging area to the North Kaibab trailhead and the Uncle Jim Trail. This trail will be separate from the Ken Patrick Trail. Mule use will be allowed on new trail sections, the Uncle Jim Trail, and the North Kaibab Trail (see "Corridor Trails" for North Kaibab Trail use).

\section{ORIENTATION AND INTERPRETATION}

\section{- Gateway Information}

In cooperation with the U.S. Forest Service, orientation services at the Kaibab Plateau visitor center at Jacob Lake will be expanded. The existing structure may be enlarged, or a new facility may be built nearby. In addition to more parking, restrooms, and a 24-hour information kiosk, the following functions will be provided:

- information/trip planning, national park day-use and backcountry permits, small-scale exhibits on the regional environment, and book sales 
- lodging and camping check-in for all NPS facilities, as well as direct phone connections for lodging/camping confirmations and reservations

\section{- Orientation Center}

The small orientation center on CC Hill will be within easy access of canyon views. The center will provide the following functions:

- an information desk, interpretive information panels, and limited book sales

- a backcountry permitting station and office, and basic hiker safety equipment sales (i.e., water bottles)

- a mule ride/tour bus registration desk

- outdoor seating, picnic areas, restrooms, drinking water, and vending machines

A contact station currently proposed at Grand Canyon Lodge will remain and will provide information and announcements of interpretive programs, as well as restrooms.

A small information station, with restrooms, will be provided on Bright Angel Point. The approved wayside exhibit plan will be implemented throughout the developed area of the North Rim.

\section{- Interpretive Facilities}

The auditorium at Grand Canyon Lodge, the amphitheater at the campground, and an extensive personal service program will remain.

To enhance the visitor experience and draw people to Walhalla Plateau, outdoor exhibits focusing on American Indian cultures, geology, and other natural resources may be added at Point Imperial.

\section{VISITOR SERVICES}

\section{- Outside the Park}

Visitor services outside the park will continue to be available in Kanab and Fredonia, as well as areas farther from the park. USFS proposals to expand lodging at Kaibab Lodge and Jacob Lake and to increase designated camping in several areas will be evaluated as part of that agency's planning process. Additional parking may be needed on adjacent national forest lands to accommodate visitors waiting to get in the park.

\section{- North Rim}

Lodging and Camping: The existing Grand Canyon Lodge visitor cabins and motel units $( \pm 200)$ will remain. To better separate employee housing from visitor accommodations, approximately 20 cabin units at the lodge and inn will be converted from employee housing to visitor lodging units. This action will increase the total number of visitor cabins to approximately 220 .

Four to six of the historic exposed frame cabins at the inn will be adaptively used; the rest will be razed and the area revegetated. This action will be implemented in compliance with the provisions of federal historic preservation laws and NPS Management Policies and will be undertaken after further consultation with the Arizona state historic preservation officer under the terms of the programmatic agreement. 
The campground will be redesigned and revegetated to protect resources and to provide additional privacy. The number of group sites and the locations of individual sites will be studied, and the number of campsites may be reduced slightly. The maximum length for vehicles in the campground will be $22^{\prime}$. The existing laundry and shower building will be replaced by a larger facility in the campground.

Food Service, Shopping, and Other Facilities: Minor changes will be made at Grand Canyon Lodge to improve visitor services, and the inn's camper store and fast-food restaurant will remain. The existing gas station will be adaptively reused for a bike rental shop, and a mobile repair unit will be provided for minor vehicle breakdowns.

At Grand Canyon Lodge some minor changes in building use will be made. All visitor vehicle parking will be removed from in front of the lodge. A drop-off area will be provided in the parking lot.

Food service, with a limited menu, will be provided for visitors at the historic inn, along with a camper store.

Picnic sites will be added near the North Kaibab trailhead and the Grand Canyon Lodge area. Picnic sites at overlooks on Walhalla Plateau will be redesigned.

Restrooms will be added at the CC Hill orientation center, while other restrooms on Bright Angel Point will remain the same. Water-conserving toilets will replace existing facilities in some areas of the Walhalla Plateau.

\section{- Winter Use}

Outside the park the U.S. Forest Service and the National Park Service will work together to provide a system of winter huts to allow access for visitors on skis or snowshoes.

Within the park the North Rim will be closed to motorized winter use, and concession facilities will remain closed. One group campsite, with portable toilets, will continue to be available. As part of the winter hut system, portable huts will be placed in three areas accessible to moderately fit skiers - Point Imperial, the Lindbergh Hill area, and CC Hill. The huts will be moved into parking lots once motorized use ends for the season. Portable toilets and firewood will be available. The maximum group size at any one hut area will follow the same maximum standards as for backcountry group campsites.

\section{CoOperation OUtSide PaRK Boundaries}

The National Park Service will consult and cooperate with its neighbors with regard to activities occurring outside park boundaries that may affect park management practices.

It is assumed that the Forest Service will continue to manage and develop Kaibab National Forest lands as directed in its management plan. The Kaibab Plateau visitor center at Jacob Lake has been opened, more nonmotorized trails and camping opportunities are being considered, and additional restaurant and lodging facilities will be provided, as proposed in the Kaibab National Forest Plan. The Arizona Highway 67 Scenic Byway corridor will continue to be intensively managed for high-quality scenic resources.

The Federal Highway Administration will reconstruct Arizona 67 from Jacob Lake to the park boundary by 1999. 


\section{OUTSIDE The PARK}

The National Park Service will work with the U.S. Forest Service to provide housing for NPS employees working at Jacob Lake at the nearby USFS housing site. Until that housing can be provided, employees will have to find housing in Fredonia or Kanab.

\section{NORTH RIM}

\section{- Housing}

Approximately 270 housing units will be constructed in existing disturbed areas to replace substandard units and units converted to visitor lodging. The average density will be 15 dwelling units per acre or higher, and the units will be designed to blend with the character and environment of the North Rim. No single-family units will be built, and only a few lower density units will be provided.

\section{- Community Services}

Current community services will be retained, and existing structures will continue to be used.

\section{- NPS Management Support Functions}

All existing NPS management support space will remain, except for the following changes. A new maintenance building will be constructed in disturbed areas and will be designed to blend with the area's historic and natural character. A new backcountry office and minor interpretive office space will be included at the North Rim orientation center at CC Hill and at Jacob Lake.

The helipad will be moved to the clearing just north of the sewage treatment plant.

A fire/safety building will be constructed in the NPS management support area.

\section{- Concessioner Management Support Functions}

Management support facilities for the concessioner will remain the same, except for the construction of a new joint transit maintenance facility at Lindbergh Hill, including parking spaces for transit and concession buses, a paved access road, a shuttle maintenance building and offices, covered bus storage, and utilities. The mule staging area will be relocated from the North Kaibab trailhead to near the new orientation center, in a location that will provide easy access to the North Kaibab trailhead; the mule concession barn will remain the same.

\section{- Utilities}

Utilities (telephone, electricity, water, and sewer) may have to be improved or provided to support functions at CC Hill and Jacob Lake. Water-conserving toilets will be placed at all the major overlooks on the Walhalla Plateau and at the Widforss trailhead. The North Rim water-supply system will have adequate capacity to handle increased demands for potable water inside the park. A new line will have to be built to the CC Hill orientation center, and a storage facility will be added at Lindbergh Hill for water hauled into or collected in this area. The wastewater treatment plant will be expanded, with a sewerline extension to CC Hill. 


\section{SUMMARY OF TUWEEP ACTIONS}

To ensure uncrowded, primitive experiences, day use limits will be established at Tuweep at a maximum of 30 vehicles or 85 visitors at one time. This total includes visitors at Toroweap Overlook, the campground, the Vulcans Throne area, and local trails. The Park Service will attempt to achieve this limit through roadside signs and other information sources first. If these means are not successful, a reservation system may be required.

The Park Service will work cooperatively with federal, state, and local agencies having jurisdiction over adjacent lands to ensure a visitor experience compatible with that offered in the park.

\section{TuWeep PlanNing Issues}

\section{- Region}

Information for visitors before they get to Tuweep is inadequate.

Closer communication between the Bureau of Land Management and the park is needed to provide visitors with information, more appropriately distribute use, and ensure resource preservation.

\section{- Visitor Experience}

Future visitor increases could degrade the present visitor experience at Tuweep.

Parking occurs directly at the overlook, with potential for harmful effects on the resource. Designated parking is inadequate.

The narrow dirt roads receive limited maintenance.

Campsites are overcrowded, and the campground is overused by groups. The campsites near Toroweap Overlook have no privacy.

\section{- Cultural and Natural Resources}

There are a large number of significant archeological and probably ethnographic resources in the area. Because Tuweep is remote, these sites are being vandalized.

Natural quiet is affected by aircraft overflights.

\section{- Utilities}

Water is limited. Chemical toilets, with high maintenance requirements, are used. 


\section{Visitor Use Patterns}

The number of day visitors to Tuweep will be limited at certain peak times of the year to maintain an uncrowded, rustic, and remote experience that is dominated by nature and solitude.

\section{ACCESS, ROADS, AND TRAILS}

The Park Service will work with Mohave County to ensure that access roads to Tuweep remain unpaved and do not change in character in order to help preserve the area's secluded and natural appearance. The Park Service will also work with the Bureau of Land Management to ensure that the natural visual quality along access roads is retained.

Existing roads inside the park will remain dirt and have limited maintenance. Vehicle sizes will be restricted to a maximum of $22^{\prime}$ in length. To reduce congestion and natural resource impacts at the rim, the parking area and toilet at Toroweap 0verlook will be removed and the area revegetated. A new 25-space parking area and toilet will be provided in an appropriate place adjacent to the existing road near the entry to the Saddle Horse Canyon trail. A small roadside pulloff will be designated at the Tuckup trailhead. These parking areas will be located to avoid ephemeral pools and other sensitive resources.

Existing trails will be maintained, including Tuckup, Saddle Horse Canyon, and access to the Lava Falls trail. The existing road from the proposed parking area will be converted to a pedestrian trail, although visitors with disabilities and service vehicles will still be allowed to drive to the rim. A new loop trail will be built from the west side of the new parking lot to the Saddle Horse Canyon trail and Toroweap Overlook.

\section{INTERPRETATION}

\section{- Gateway Information}

Park managers will work with the Bureau of Land Management, Mohave County, Pipe Spring National Monument, and the tourism hub communities of Kanab and Fredonia to provide information about Tuweep to visitors and to monitor resource preservation throughout the entire area.

Information signs about Tuweep will be placed along all three major county access roads to inform people about the limitations at Tuweep for accommodating day and overnight use, as well as to provide safety information.

Grand Canyon National Park managers will also work with staff at Pipe Spring National Monument to provide information about Tuweep. Staff at the monument may be able to make campsite reservations for visitors and to issue day use permits during peak seasons if a reservation system becomes necessary; no facility additions are anticipated, other than a small exhibit and information panel on Tuweep.

Use permits may also be distributed in Fredonia, Kanab, or St. George by other federal agencies. 


\section{- Tuweep}

An information/interpretive kiosk may be provided at a small roadside pulloff just inside the park boundary. Waysides may also be provided at the parking area for Toroweap 0verlook.

\section{Visitor SeRVices}

The Bureau of Land Management will continue to provide camping opportunities outside the park.

During high use seasons (spring and fall) a camping reservation system may be established for the Tuweep campground. The two campsites at the overlook will be removed, and two replacement sites will be provided at the existing campground. One campsite will be designated as a group site. A maximum of six people will be allowed at the individual campsites and 11 people at the group site. However, there will be a limit of two private vehicles at each individual campsite and four vehicles at the group campsite. Commercial uses at Tuweep will be tightly controlled, and requests for such activity will be evaluated on a case-by-case basis.

\section{AREA OPERATIONS}

\section{HOUSING}

To replace the substandard seasonal housing, either a private residence outside the park will be rented or a new unit built in the park. Office space may be expanded slightly to provide adequate space for the seasonal ranger.

\section{UTILITIES}

The septic and water catchment systems at the ranger station will be rehabilitated. A septic system will be developed at the seasonal ranger unit (if needed). All public toilets will be converted to water-conserving models. A toilet will be placed at the new parking lot for the overlook. 


\section{SUMMARY OF CORRIDOR TRAIL ACTIONS}

The vision for the corridor trails is to maintain the traditional character of the trails and to minimize crowding, visitor use conflicts, and resource impacts. Drinking water and toilets will be provided at critical locations for visitor safety and to reduce environmental impacts.

Hiking will not be limited on any trails, but resource impacts and user conflicts due to mule use will be reduced. Present overnight lodging and camping opportunities will remain largely unchanged, pending additional planning for Phantom Ranch.

\section{CoRridor Trails PlanNing Issues}

\section{- Visitor Experience}

Visitor information is lacking, so visitors are not always prepared for safe hiking trips.

Trails are often overcrowded.

Mule use on trails causes conflicts with hikers.

\section{- Cultural and Natural Resources}

The historic character, cultural landscape, and archeological resources near the trails are being impacted by high visitor use.

Intensive trail maintenance is needed due to mule use, and borrow pits in the inner canyon are used for maintenance purposes.

Excess water from the transcanyon waterline is released to Garden Creek, with resulting impacts on the natural habitat.

\section{- Utilities}

Water-conserving toilet facilities are lacking.

Some trailheads lack restrooms, drinking water, or phones.

\section{VISITOR EXPERIENCE}

\section{ACCESS AND TRAILS}

Sections of the main trails will be hardened with a natural material that blends well with the environment, that is permeable, that provides good traction, and that will significantly reduce the need to use borrow material. The main corridor trails may be widened in a few limited locations to facilitate safe passing of mules and hikers. Existing borrow areas will be rehabilitated.

Concessioners will be made much more responsible for corridor trail maintenance. Programs and exhibits at all corridor trailheads with mule and hiker use will help educate visitors about stock trails and hiker etiquette. Private stock use opportunities will continue to be available; the park's revised Backcountry Management Plan will address specific details about such use. 
An active monitoring program, along with indicators and standards, will be established to determine carrying capacities for visitors and stock on the corridor trails. The Hermit and Grandview Trails will also be the subject of a separate monitoring program and carrying capacity study to ensure that resources and visitor experiences do not significantly change on those trails as a result of dispersing some corridor trail use to them. Measures may be taken under the Backcountry Management Plan if carrying capacities are exceeded.

The corridor trail system will be designated as part of the Arizona Trail, but restrictions on bicycle, livestock, and overnight hiking use will continue, consistent with the park's Backcountry Management Plan.

\section{- South Rim}

The Hermit and Grandview Trails will be suggested as alternatives to the corridor trails for visitors with experience hiking in the Grand Canyon. However, neither trail use nor maintenance will be increased to levels that will alter their status as threshold trails. Current mule use will remain at a maximum of 40 visitor mule trips (60 passes) on the Bright Angel Trail and 20 mule trips (20 passes) on the South Kaibab Trail; however, no additional pack strings will be allowed for carrying visitor packs into or out of the canyon.

\section{- North Rim}

The mule ride concessioner, in conjunction with the Park Service, will begin immediately to reduce resource impacts and user conflicts now occurring on the North Kaibab Trail. This will be accomplished by hardening the trail from the rim to the tunnel (using cobbling or similar material), and by educating all trail users about mules on trails.

Because trail use could increase as a result of use at the nearby CC Hill orientation center, a monitoring system will continue until new use patterns are established. If resource damage and visitor use conflicts are not adequately mitigated by using these measures, then the number of mules allowed on the trail will be reduced to a level comparable to that on the Bright Angel Trail.

The Old Bright Angel Trail will be slightly upgraded from route/wild trail standards to primitive trail standards, as defined in the park's Backcountry Management Plan. A signed trail connection will be established from a small pullout next to Six Rock Meadow to the trailhead. Stock use will not be allowed on either of these trails.

\section{INTERPRETATION}

At Indian Garden visitor programs will be provided, and a small amphitheater will be added near the picnic area. A small building (the former ranger station), which is used for storage, will be converted to a visitor contact station.

The roving interpreter program will be expanded, especially on the South Rim corridor trails.

\section{Visitor SeRVices}

The capacity of overnight accommodations at Phantom Ranch and the Bright Angel campground will not be increased but could be decreased pending the completion of a development concept plan for the area.

The campgrounds at Indian Garden and Cottonwood will remain the same size. 


\section{Area Operations}

\section{HOUSING}

A development concept plan for Phantom Ranch will address needed facilities. At Indian Garden housing will remain the same, except one house now used for storage will be converted back to housing for an interpreter if floodplain safety concerns can be adequately addressed.

\section{MANAGEMENT SUPPORT}

Management support facilities will not be changed.

\section{UTILITIES}

Existing toilets along the trails will be replaced with water-conserving models, and more toilets will be added, if needed.

\section{Other AREAS}

At Lees Ferry an orientation center with facilities for the river trip safety talks and an exhibit area for the historic boat collection will be constructed in cooperation with Glen Canyon National Recreation Area, after the 1985 Development Concept Plan has been amended. 


\section{INTERRELATIONSHIP OF THIS PLAN WITH OTHER PLANS \\ AND PROJECTS}

Plans and studies used to develop this document are listed in the bibliography. The plans listed below directly influenced the development of the General Management Plan. Separate action plans that will need to be prepared to implement this plan are also identified.

\section{National Park Service}

\section{- Wilderness}

A wilderness proposal was prepared in 1980 at the request of Congress; it was updated in 1993 and awaits further action. Wilderness designation was proposed for 1,109,257 acres, with an additional 29,820 acres of potential wilderness, pending the resolution of park boundary and motorized riverboat issues.

NPS Management Policies (1988) require that wilderness study areas be managed the same as designated wilderness and that no actions be taken that would diminish wilderness suitability until the legislative process for wilderness designation has been completed.

Therefore, this General Management Plan treats all proposed wilderness areas as wilderness and anticipates the final resolution of wilderness issues and the preparation of a wilderness management plan as future actions. All actions proposed in this document, and all future implementation plans based on it (such as the Backcountry Management Plan, the Colorado River Management Plan, and the Fire Management Plan) will be consistent with NPS wilderness policy requirements.

\section{- Resource Management}

The park's Resource Management Plan (updated in 1994) guides the management of all park resources. It provided guidance throughout the planning process.

\section{- Backcountry Management}

The park's 1988 Backcountry Management Plan will be updated to be consistent with the direction provided in the management objectives and other sections of this plan. A wilderness experience will be provided in all proposed wilderness areas. Ways to manage use in backcountry areas, including the corridor trails and Tuweep, will generally be addressed in the revised plan according to the direction provided in this General Management Plan, including the possibility of day use permits or other restrictions in certain areas.

\section{- Colorado River Management}

The park's 1989 Colorado River Management Plan will be revised as needed to conform with the direction given in the management objectives of this General Management Plan. The use of motorboats will be addressed in the revised plan, along with other river management issues identified through the scoping process. The revised plan will also conform to NPS direction and 
responsibilities as set forth in the Operation of Glen Canyon Dam Final Environmental Impact Statement (Bureau of Reclamation).

\section{- Fire Management}

The park's 1992 Fire Management Plan will be updated to be consistent with the direction in the management objectives and other sections of this document. It will also specifically address the restoration of the natural fire regime in wilderness areas, using practices consistent with the wilderness management plan.

\section{- Aircraft Management}

In September 1994 the National Park Service presented the Report on Effects of Aircraft Overflights on the National Park System to Congress, in compliance with Public Law 100-91 (NPS 1994e). The report contains specific recommendations for substantially restoring the natural quiet and experience of the park relative to aircraft overflights. This General Management Plan and the report's recommendations are consistent with each other and with legislation and policy. Future planning will address aircraft overflight issues in detail.

\section{- Other Plans}

The park's 1985 Statement for Management, the 1989 Land Protection Plan, the 1994 Architectural Character Guidelines, and the 1994 Statement of Interpretation were also consulted in developing this General Management Plan.

\section{Bureau OF LANd MANAgement}

In 1992 the Bureau of Land Management released the Arizona Strip District, Resource Management Plan and Final Environmental Impact Statement, which was important in developing the management direction for the Tuweep area. The management objectives and proposed management actions for lands adjacent to Tuweep are similar to and compatible with the park's management objectives and visions.

\section{U.S. Forest Service}

\section{- Kaibab National Forest}

The 1987 Kaibab National Forest Plan (amended in 1990) defines the mission, goals, objectives, and management direction for most of the national forest lands directly adjacent to developed areas on the South and North Rims. The management goals and objectives for recreation and visitor use management in Kaibab National Forest are compatible with the visions for Grand Canyon National Park established during this general management planning process. The USFS goals and objectives were carefully considered when developing the alternatives considered in this document. 


\section{- Kaibab National Forest Land Exchange Environmental Impact Statement}

The U.S. Forest Service has been analyzing the environmental impacts associated with the exchange of a large contiguous parcel of land ( \pm 640 acres) adjacent to development in Tusayan for $\pm 1,200$ acres of inholdings scattered throughout the Tusayan ranger district of Kaibab National Forest.

The purpose of the proposed land exchange is to manage and influence the development of land located within the Tusayan ranger district to ensure that the appropriate level of visitor and community services are provided and that resource values of the national park and national forest are protected. The exchange could help minimize potentially adverse impacts that could otherwise result from piecemeal, uncoordinated development of private and federal lands.

If completed, the land exchange would consolidate lands adjacent to an existing urban area and allow for housing and related community services to be developed for Forest Service and Park Service employees. Visitor accommodations, commercial enterprises, and park-related interpretive facilities could also be provided.

As a cooperating agency, the National Park Service is working closely with the Forest Service for two primary reasons: (1) to help ensure that the land exchange would not adversely affect the national park, and (2) to see if needed park housing, community services, and possible gateway information, staging/parking, and public transit facilities could be a part of the development.

\section{Tusayan Planning Committee}

In 1993 Coconino County formed the Tusayan Planning Committee to create goals and policies to be used as guidance by Coconino County officials when deciding issues with a bearing on Tusayan. The Tusayan Area Plan, which was largely completed by December 1994, will guide future land use decisions in Tusayan. A park representative from the general management planning team served on the committee and provided input to ensure that decisions made in the plan were positive for park resources and visitors, and that any actions will create an improved gateway to the Grand Canyon's South Rim.

\section{Regional Transportation Committee}

In 1993 a regional transportation committee was formed to provide a process for making regional transportation decisions. The committee's purpose is to help analyze transportation options outside the park in conjunction with the park's general management planning process.

The committee, which is coordinated by the Northern Arizona Council of Governments, includes numerous public and private entities. A steering committee helps direct the whole committee. A member of the Grand Canyon general management planning team was on the overall committee and the steering committee.

Through this committee, a regional transportation study is being conducted, focusing on regional intermodal transportation solutions to help solve traffic congestion within the park. The study is concentrating on the feasibility of establishing staging areas in existing communities and developing efficient alternative transportation modes to the South Rim. 


\section{PHASING FOR THE GENERAL MANAGEMENT PLAN}

Under this General Management Plan proposed facilities will be constructed in existing disturbed areas, and existing structures will be adaptively reused. Before existing facilities can be reused for new purposes, present functions must be relocated. In some cases a relocation must be preceded by three or four other moves to be done most efficiently and to keep from disturbing new lands. Therefore a sequenced phasing plan is needed to coordinate various actions. Two phases are proposed:

Phase 1 - 1995-2002: Actions primarily related to improving transportation, or initial actions in a series of adaptive uses.

Phase 2 - 2003-2010: Actions that are lower priority or must wait for phase 1 items to be completed before they can be started.

The following additional information is provided with each action item:

- Sequence - Refers to whether an action can be done immediately, meaning it could be done first, or whether another action must be taken beforehand, which would mean it could be done second, third, or fourth.

- Year Estimated - The year an action can be expected to be completed. This phasing plan anticipates all major actions being completed by 2010.

- Cost - A rough estimate of the capital cost to complete an action and an estimate of operating costs that would be required to operate and maintain a facility. 0perating costs are only given for facilities operated or maintained by the National Park Service.

- Funding - An early indication of where funding may come from to complete an action.

- Compliance - An indication of additional compliance required for the specific actions listed. Compliance with both the National Environmental Policy Act (NEPA) and the National Historic Preservation Act (NHPA) is considered.

\section{SOUTH RIM}

\section{PhASE 1}

- Transportation

- Expand the shuttle bus fleet, season, and area of coverage to provide improved service as soon as possible. This item includes replacing existing rolling stock to improve service (but not to 2010 standards) and expanding maintenance facilities and bus shelters.

Sequence: First

Year Estimated: 1998

Cost: $\quad \$ 16,000,000$ capital, $\$ 2,000,000$ annual operations 
Funding: Congress

Compliance: Environmental assessment or categorical exclusion, NHPA sec. 106 consultation

- Construct the orientation/transit center and a portion of the associated parking lot near Mather Point. This includes all utilities, roads, structures, and trails to make this center operational.

Sequence: $\quad$ First

Year Estimated: 1999

Cost: $\quad \$ 11,243,200$ capital, $\$ 300,000$ annual operations

Funding: $\quad$ Congress for roads, Congress/private for center

Compliance: Environmental assessment, NHPA sec. 106 consultation

- Construct the gateway information center in Tusayan and a portion of the associated parking lot. This includes all utilities, road changes, structures, and trails to make this facility operational. This facility will be served by a concessioner-operated shuttle system (privately funded).

Sequence: $\quad$ First

Year Estimated: 1999

Cost: $\quad \$ 10,707,800$

Funding: $\quad$ Private, with portion from Congress

Compliance: Environmental assessment (with U.S. Forest Service), NHPA sec. 106 consultation; none if privately constructed on private land

- Develop a transportation system from the Tusayan gateway information center to the Mather Point orientation/transit center.

Sequence: First

Year Estimated: 1999

Cost: $\quad \$ 20,000,000$

Funding: $\quad$ Private, with agreement to allow capture of investment

Compliance: Environmental assessment, NHPA sec. 106 consultation (unless covered in the Tusayan gateway information center documents)

- Construct bike and pedestrian trails.

Sequence: $\quad$ First

Year Estimated: 2000

Cost: $\quad \$ 12,948,000$ capital, $\$ 300,000$ annual operations

Funding: $\quad$ Congress/private/concessioner

Compliance: Environmental assessment, NHPA sec. 106 consultation

- Construct Desert View bypass road, new entrance station, and a portion of the orientation center parking lot.

Sequence: $\quad$ Second, after relocating concessioner housing

Year Estimated: 2000

Cost: $\quad \$ 2,926,100$

Funding: $\quad$ Congress

Compliance: Environmental assessment, NHPA sec. 106 consultation 
When these actions are taken, several parking lots in Grand Canyon Village may be removed, including the gravel lot in the railroad yard, the Bright Angel lot, roadside parking along the rim, and the El Tovar/Verkamp's lot. However, the new road segments needed to allow the main roads to be closed to all automobiles will not yet have been built, so some auto traffic (overnight guests) will still be interfacing with transit vehicles on main roads. Also at this time the overlooks on East Rim Drive will be closed during the high use season and served by buses. The Desert View parking lot may be removed.

\section{- Information / Education}

- Improve dissemination of park information. This includes networking with regional visitor centers, getting information in airports, on Internet, and in the mail to potential visitors, and using video and telecommunications, along with providing better information to providers (such as training, staff in some cases, publications, and hardware).

Sequence: First

Year Estimated: 1997

Cost: $\quad \$ 109,200$ capital, $\$ 100,000$ annual operations

Funding: $\quad$ Congress/concessioner

Compliance: None

\section{- Visitor Services}

- Convert community building to an education center. This includes creating Grand Canyon Field Institute space and space for interpretive programs and group education. Existing uses will be removed.

Sequence: First

Year Estimated: 1996

Cost: $\quad \$ 2,058,900$ capital,

$\$ 50,000$ annual operations

Funding: Private

Compliance: NHPA sec. 106 consultation

- Clean up the Orphan Mine site and reopen to visitors.

Sequence: First

Year Estimated: 1997

Cost: $\quad \$ 624,000$

Funding: Congress

Compliance: Environmental assessment or categorical exclusion, NHPA sec. 106 consultation

- Relocate the mule barn and corral to a new facility on the west edge of the village.

Sequence: First

Year Estimated: 2000

Cost: $\quad \$ 1,802,600$

Funding: $\quad$ Concessioner

Compliance: Environmental assessment, NHPA sec. 106 consultation 
- Construct a new store where the original Babbitt's store once stood and convert part of the original post office (now the magistrate's building) to community/visitor uses.

Sequence: $\quad$ First for the store and second for the magistrate's building after relocating the fee collection function to the gateway information center in Tusayan

Year Estimated: 2000

Cost: $\quad \$ 2,577,200$

Funding: $\quad$ Concessioner

Compliance: Categorical exclusion, NHPA sec. 106 consultation

- Rehabilitate mule barn for an American Indian cultural center.

Sequence: $\quad$ Second, after relocating mule operation

Year Estimated: 2002

Cost: $\quad \$ 2,808,000$ capital, $\$ 100,000$ annual operations

Funding: Undetermined

Compliance: NHPA sec. 106 consultation

The above actions, together with the construction of the orientation center at Mather Point, will allow improved interpretation, removal of the backcountry reservations office (function to be relocated to the orientation center), and the existing visitor center to function as a museum until the powerhouse is rehabilitated in a later phase.

\section{- Housing}

- Relocate Pinyon Park trailers.

Sequence: First

Year Estimated: 1998

Cost: $\quad \$ 500,000$

Funding: $\quad$ Concessioner/private/Congress

Compliance: $\quad$ Environmental assessment, NHPA sec. 106 consultation

- Construct new housing; relocate existing trailers from Desert View concessioner housing area to shared housing area.

Sequence: $\quad$ First

Year Estimated: 1999

Cost: $\quad \$ 2,480,000$ capital, $\$ 35,000$ annual operations

Funding: $\quad$ Concessioner/Congress

Compliance: Environmental assessment or categorical exclusion, NHPA sec. 106 consultation

- Construct or encourage construction of housing in the Tusayan area for NPS and concessioner use.

Sequence: $\quad$ First

Year Estimated: 1999

Cost: $\quad \$ 7,524,200$ capital, $\$ 80,000$ annual operations

Funding: $\quad$ Private/concessioner/Congress

Compliance: $\quad$ None if privately built on private lands; otherwise, environmental assessment and NHPA sec. 106 consultation

- Construct first phase of apartment/dormitory housing at Pinyon Park. 
Sequence: $\quad$ Second, after relocating Pinyon Park trailers

Year Estimated: 2000

Cost: $\quad \$ 10,163,400$ capital, $\$ 160,000$ annual operations

Funding: $\quad$ Concessioner/Congress

Compliance: Environmental assessment, NHPA sec. 106 consultation

Along with the above actions, as many jobs as possible will be moved to Flagstaff or Williams.

- Management Support

- Relocate dry storage to the former Southgate parking area.

Sequence: First

Year Estimated: 1996

Cost: $\quad \$ 15,600$

Funding: $\quad$ Congress

Compliance: None

- Construct joint fire response facility; vacate Fred Harvey fire/safety building, equipment bays in the NPS maintenance shop, YACC camp, and some offices in the ranger operations building.

Sequence: First

Year Estimated: 1997

Cost: $\quad \$ 2,457,100$ capital, $\$ 40,000$ annual operations

Funding: $\quad$ NPS concession fund

Compliance: Environmental assessment or categorical exclusion, NHPA sec. 106 consultation

- Construct NPS maintenance/warehouse facility and construct concessioner transportation facility at the existing dry dump. This includes extending utilities.

Sequence: $\quad$ First

Year Estimated: 2000

Cost: $\quad \$ 17,757,200$

Funding: $\quad$ Concessioner/Congress

Compliance: Environmental assessment or categorical exclusion, NHPA sec. 106 consultation

The above actions will make the existing dry storage area available for expanded shuttle maintenance, relocation of concessioner bus operations, and the construction of NPS maintenance facilities.

\section{PHASE 2}

\section{- Transportation}

- Construct road segments to remove private vehicles from the rim area and main village roads. This includes an entrance off the south entrance road for the Mather campground and RV campground, a road connection from the employee housing area to the business center, and a new road from Center Road to the Maswik area.

Sequence: First

Year Estimated: 2003

Cost: $\quad \$ 2,574,100$ capital, $\$ 30,000$ annual operations 
Funding: $\quad$ Congress

Compliance: Environmental assessment, NHPA sec. 106 consultation

- Further expand the shuttle bus fleet and the area of coverage, including further expansion of the maintenance facility.

Sequence: $\quad$ Second, after first expansion of fleet

Year Estimated: 2004

Cost: $\quad \$ 11,993,100$ capital, $\$ 1,500,000$ annual operations

Funding: $\quad$ Congress

Compliance: $\quad$ Covered by phase 1 compliance

- Finish parking lot at Mather Point.

Sequence: $\quad$ Second, after phase 1 of parking lot

Year Estimated: 2005

Cost: $\quad \$ 2,251,000$

Funding: $\quad$ Congress

Compliance: $\quad$ Covered by phase 1 compliance

The above actions will fully implement the proposed transportation system. Additional parking at the Tusayan gateway information center could happen as needed and would be privately funded. Additional buses will be needed as visitation increases.

\section{- Information / Education}

- Construct the Desert View orientation/transit center.

Sequence: $\quad$ Second, after relocating parking

Year Estimated: 2003

Cost: $\quad \$ 4,266,300$ capital, $\$ 100,000$ annual operations

Funding: $\quad$ Congress/private

Compliance: Environmental assessment or categorical exclusion, NHPA sec. 106 consultation

- Convert the horse barn to interpretive uses.

Sequence: Third, same as powerhouse (see next action)

Year Estimated: 2004

Cost: $\quad \$ 1,774,600$ capital, $\$ 75,000$ annual operations

Funding: $\quad$ Congress/private

Compliance: NHPA sec. 106 consultation

- Convert powerhouse to education center.

Sequence: $\quad$ Third, after relocating NPS maintenance and concessioner

Year Estimated: 2005 maintenance/commissary

Cost: $\quad \$ 6,601,500$ capital, $\$ 250,000$ annual operations

Funding: $\quad$ Congress/private

Compliance: NHPA sec. 106 consultation

The above actions will complete the facility-related components of the information/education proposals. It will also allow the existing visitor center to be used exclusively as park headquarters. 


\section{- Visitor Services}

- Convert the historic laundry to food service; convert the maintenance shop to a bike rental shop.

Sequence: Third, same as powerhouse

Year Estimated: 2001 for bike rental, 2004 for the rest

Cost: $\quad \$ 3,982,500$

Funding: Concessioner

Compliance: NHPA sec. 106 consultation

- Construct new trading post and food service at Desert View; remove the existing trading post.

Sequence: $\quad$ Second, after relocating parking

Year Estimated: 2003

Cost: $\quad \$ 1,310,800$

Funding: $\quad$ Concessioner

Compliance: Environmental assessment or categorical exclusion, NHPA sec. 106 consultation

- Add 50 campsites at Desert View.

Sequence: First

Year Estimated: 2003

Cost: $\quad \$ 305,200$

Funding: $\quad$ Congress

Compliance: Environmental assessment, NHPA sec. 106 consultation

- Redesign the RV campground at the trailer village.

Sequence: $\quad$ Fourth, after relocating Pinyon Park trailers and constructing two phases of new housing at Pinyon Park

Year Estimated: 2005

Cost: $\quad \$ 1,080,000$

Funding: $\quad$ Concessioner

Compliance: $\quad$ Categorical exclusion, NHPA sec. 106 consultation

- Convert five dormitories to visitor use.

Sequence: $\quad$ Fourth, after relocating Pinyon Park trailers and constructing two phases of housing at Pinyon Park.

Year Estimated: 2008

Cost: $\quad \$ 4,693,100$

Funding: $\quad$ Concessioner

Compliance: NHPA sec. 106 consultation

- Replace Yavapai West units with new, two-story units (includes removing motel units plus the Thunderbird and Kachina Lodges).

Sequence: $\quad$ First

Year Estimated: 2010

Cost: $\quad \$ 9,506,700$

Funding: $\quad$ Concessioner 
Compliance: Environmental assessment, NHPA sec. 106 consultation

The above items, in addition to some rearranging of spaces at the Bright Angel Lodge, Hermits Rest, Lookout Studio, and Desert View Watchtower, will complete the visitor services portion of the plan.

\section{- Housing}

- Construct the second phase of apartment/dormitory housing at Pinyon Park.

Sequence: $\quad$ Third, after relocating trailers and first phase of housing

Year Estimated: 2003

Cost: $\quad \$ 13,968,600$ capital, $\$ 160,000$ annual operations

Funding: $\quad$ Congress/concessioner

Compliance: Covered by phase 1 compliance

- Construct second phase of housing in Tusayan.

Sequence: $\quad$ Second, after phase 1

Year Estimated: 2005

Cost: $\quad \$ 7,200,000$

Funding: $\quad$ Private/concessioner/Congress

Compliance: Covered by phase 1 compliance

- Complete housing at Desert View.

Sequence: $\quad$ Second, after phase 1 of housing

Year Estimated: 2006

Cost: $\quad \$ 5,307,800$ capital, $\$ 80,000$ annual operations

Funding: $\quad$ Congress/concessioner

Compliance: Covered by phase 1 compliance

The above actions will satisfy the need for housing as depicted in this plan through 2010.

- Management Support

- Rehabilitate NPS maintenance and warehouse complex for concessioner maintenance and commissary.

Sequence: $\quad$ Second, after relocating NPS maintenance and warehouse

Year Estimated: 2003

Cost:

$\$ 3,395,600$

Funding: $\quad$ Concessioner

Compliance: NHPA sec. 106 consultation

- Remove the public garage function from the general offices building and rehabilitate for additional offices.

Sequence: $\quad$ Second, after relocating concessioner transportation maintenance

Year Estimated: 2003

Cost: $\quad \$ 851,500$

Funding: $\quad$ Concessioner

Compliance: NHPA sec. 106 consultation 
- Construct new NPS maintenance, NPS administration, and concessioner maintenance facilities at Desert View.

Sequence: $\quad$ First

Year Estimated: 2007

Cost: $\quad \$ 2,557,700$

Funding: Congress/concessioner

Compliance: Environmental assessment, NHPA sec. 106 consultation

The above actions will allow the concessioner's personnel building to be removed and several third-in-sequence actions described above in the information/education section and visitor services section.

Together all of these actions are crucial to the success of the plan, either because they are on the critical path or because the action itself is important to achieving the park's overall vision. Many other actions are not listed here, either because they could happen at almost anytime or because they are less important to the success of implementing the plan.

\section{NORTH RIM}

\section{PhASe 1}

- Transportation

- Construct a parking area at CC Hill, access road, and transit shelter. Sequence: First

Year Estimated: 2001

Cost: $\quad \$ 1,613,800$

Funding: $\quad$ Congress

Compliance: Environmental assessment, NHPA sec. 106 compliance

- Establish a shuttle fleet on the North Rim, with bus shelters and a maintenance facility at Lindbergh Hill.

Sequence: First

Year Estimated: 2001

Cost: $\quad \$ 5,070,600$ capital, $\$ 1,110,900$ annual operations

Funding: $\quad$ Congress

Compliance: Environmental assessment or categorical exclusion, NHPA sec. 106 consultation

The above actions, in conjunction with expanding the concessioner's bus service to Walhalla Plateau, will complete the transit portion of the proposed transportation system.

- Information / Education

- Expand the Kaibab Plateau visitor center at Jacob Lake. 
Sequence: $\quad$ First

Year Estimated: 1998

Cost:

Funding:

$\$ 1,969,700$ capital, $\$ 160,000$ annual operations

Compliance: Environmental assessment (with U.S. Forest Service), NHPA sec. 106

consultation

- Construct the CC Hill orientation center.

Sequence: $\quad$ First, but concurrent with roads and parking

Year Estimated: 2001

Cost:

Funding:

$\$ 2,246,400$ capital, $\$ 60,000$ annual operations

Compliance: Covered by compliance for roads and parking

The above actions will put the National Park Service in a position to better distribute visitor use and to consider day reservations when warranted.

- Visitor Services

- Redesign the campground and construct new shower/laundry facility.

Sequence:

First

Year Estimated: 1998

Cost:

$\$ 531,600$

Funding: Concessioner/Congress

Compliance: Environmental assessment or categorical exclusion, NHPA sec. 106 consultation

- Convert cabins from employee housing to visitor lodging.

Sequence: Second, after constructing new employee housing

Year Estimated: 1999

Cost: $\quad \$ 1,198,100$

Funding: $\quad$ Concessioner

Compliance: NHPA sec. 106 consultation

- Convert the gas station to a bike rental facility.

Sequence: $\quad$ Second, after establishing a day parking lot and closing the gas station

Year Estimated: 2002

Cost: $\quad \$ 113,600$

Funding: $\quad$ Concessioner

Compliance: None

- Housing

- Construct employee housing for both concessioner employees and NPS employees (first phase only).

Sequence: $\quad$ First

Year Estimated: 1998

Cost: $\quad \$ 9,100,000$ capital, $\$ 35,000$ annual operations 
Funding: $\quad$ Congress/concessioner

Compliance: Environmental assessment, NHPA sec. 106 consultation

- Management Support

- Construct a new NPS maintenance facility. Rehabilitate historic maintenance buildings for additional office space.

Sequence: $\quad$ First

Year Estimated: 1999

Cost: $\quad \$ 4,697,800$

Funding: $\quad$ Congress

Compliance: Environmental assessment or categorical exclusion, NHPA sec. 106 consultation

\section{PHASE 2}

\section{- Transportation}

- Construct bike trails on Bright Angel Point and on the Walhalla Plateau. Sequence: First

Year Estimated: 2003

Cost: $\quad \$ 9,828,000$

Funding: Congress/concessioner

Compliance: Environmental assessment, NHPA sec. 106 consultation

\section{- Housing}

- Construct remaining housing.

Sequence: $\quad$ Second, after phase 1 housing

Year Estimated: 2007

Cost: $\quad \$ 10,351,700$

Funding: $\quad$ Congress/concessioner

Compliance: $\quad$ Covered by phase 1 compliance for housing 


\section{Bureau of Land Management, U.S. Department of the Interior}

1992 Arizona Strip District, Resource Management Plan and Final Environmental Impact Statement.

\section{Bureau of Reclamation, U.S. Department of the Interior}

1995 Operation of Glen Canyon Dam Final Environmental Impact Statement.

\section{Grand Canyon Improvement Association}

1994 "The Tusayan Community Development Plan."

\section{National Park Service, U.S. Department of the Interior}

1965 NPS-48: Concessions Policy Guideline. Washington, DC.

1974a Draft Environmental Assessment, Grand Canyon Corridor Development Concept Plan, Grand Canyon National Park. Grand Canyon National Park, AZ.

1974b National Register of Historic Places Inventory-Nomination Forms: El Tovar Hotel, El Tovar Stables, Grand Canyon Railroad Station, Grandview Mine, Hermit's Rest Concession Building, Superintendent's Residence, Tusayan Ruins, Water Reclamation Plant. On file at Grand Canyon National Park, AZ.

1975 National Register of Historic Places Inventory-Nomination Forms: Buckey 0'Neill Cabin, Grand Canyon Village Historic District, Rangers' Dormitory. On file at Grand Canyon National Park, AZ.

1976a Draft Wilderness Environmental Impact Statement, Grand Canyon National Park. Denver Service Center.

1976b Final Environmental Statement, Proposed Development Concept, Grand Canyon Village, Grand Canyon National Park, Arizona. Denver Service Center.

1976c Master Plan, Grand Canyon National Park. Grand Canyon National Park, AZ.

1980 Wilderness Recommendation, Grand Canyon National Park. Denver Service Center.

1982a National Register of Historic Places Inventory-Nomination Forms: Cross Canyon Corridor Historic District; Grand Canyon Inn and Campground, North Rim; Grand Canyon Lodge, North Rim; Grand Canyon North Rim Headquarters. On file at Grand Canyon National Park, AZ.

1982b NPS-2: Planning Process Guideline. Washington, DC. 
1984 Water Resources Management Plan, Grand Canyon National Park. Grand Canyon National Park, AZ.

1985a "Desert View Waterline: Archeological Testing 1985, with Addendum." On file at Grand Canyon National Park, AZ.

1985b Environmental Assessment, Development Concept Plan, Lees Ferry. Glen Canyon National Recreation Area, AZ.

1985c Statement for Management: Grand Canyon National Park. Grand Canyon National Park, $\mathrm{AZ}$.

1986a Final Environmental Assessment for the Development Concept Plan for Indian Garden: Grand Canyon National Park. Denver Service Center.

1986b National Register of Historic Places Inventory-Nomination Form: Trans-Canyon Telephone Line. On file at Grand Canyon National Park, AZ.

1987a National Register of Historic Places Inventory-Nomination Forms: Grand Canyon Park Operations Buildings; Grand Canyon Power House; Mary Jane Colter Buildings. On file at Grand Canyon National Park, AZ.

1988a Backcountry Management Plan, Grand Canyon National Park. Grand Canyon National Park, AZ.

1988b Draft Development Concept Plan and Environmental Assessment: North Rim, Grand Canyon National Park, Arizona. Grand Canyon National Park, AZ.

1988c NPS-76: Housing Design and Rehabilitation Guideline. Washington, DC.

1988d Management Policies. Washington, DC.

1989a "Collection Storage Plan, Grand Canyon National Park." Report prepared by Curatorial Services Division, Washington. On file at Grand Canyon National Park, AZ.

1989b Colorado River Management Plan, Grand Canyon National Park. Grand Canyon National Park, AZ.

1989c Land Protection Plan, Grand Canyon National Park. Grand Canyon National Park, AZ.

1989d Wayside Exhibit Proposals, Grand Canyon National Park. Harpers Ferry Center.

1990a Development Concept Plan, North Rim Visitor Facilities, Draft Supplemental Environmental Statement to the Final Master Plan and Environmental Impact Statement: Grand Canyon National Park, Arizona. Prepared in cooperation with Kaibab National Forest. Grand Canyon National Park, AZ. 
1990b "Position Management Plan, Grand Canyon National Park, Arizona." On file at Grand Canyon National Park, AZ.

1990c Transportation Study: South Rim Village, Grand Canyon National Park, Arizona. Denver Service Center.

1991a Environmental Assessment: Construct Employee Housing, Grand Canyon National Park. Denver Service Center.

1991b NPS-77: Natural Resources Management Guideline. Washington, DC.

1991c Phantom Ranch, Grand Canyon National Park: Rural Historic District Landscape Inventory. Grand Canyon National Park, AZ.

1991d "Potable Water Supply and Treatment Alternatives for Grand Canyon National Park." On file at Grand Canyon National Park, AZ.

1991e Statement for Interpretation and Visitor Services: Grand Canyon National Park. Grand Canyon National Park, AZ.

$1991 f$ "Study Report: Housing and Community Facilities, South Rim Village, Grand Canyon National Park." Denver Service Center.

1992a Fire Management Plan, Grand Canyon National Park. Grand Canyon National Park, AZ.

1992b General Management Plan / Environmental Impact Statement Scoping Summary: Grand Canyon National Park. Denver Service Center.

1992c Visitor Use Management Workshop Findings and Recommendations, Grand Canyon National Park. Denver Service Center.

1993a "Draft Rehabilitation Plan and Cultural Landscape Recommendations for NPS Housing: Grand Canyon Village Historic District, Grand Canyon National Park." On file at Grand Canyon National Park, AZ.

1993b Preliminary Alternatives Workbook: Grand Canyon National Park, Arizona, General Management Plan. Denver Service Center.

1993c The Secretary of Interior's Guidelines for the Treatment of Historic Landscapes. Washington, DC.

1994a Grand Canyon National Park, Architectural Character Guidelines. Denver Service Center.

1994b NPS-28: Cultural Resources Management Guideline. Washington, DC. 
1994c "Draft Grand Canyon Natural and Cultural Resources Management Plan: Grand Canyon National Park, Arizona." On file at Grand Canyon National Park, AZ.

1994d National Register of Historic Places Inventory-Nomination Form: Orphan Mine. On file at Grand Canyon National Park, AZ.

$1994 \mathrm{e}$ Report to Congress, Report on Effects of Aircraft Overflights on the National Park System. Draft. Washington, DC.

$1994 \mathrm{f}$ Statement of Interpretation, Grand Canyon National Park. Grand Canyon National Park, $\mathrm{AZ}$.

1995a Draft General Management Plan and Environmental Impact Statement, Grand Canyon National Park. Denver Service Center.

1995b Final General Management Plan and Environmental Impact Statement, Grand Canyon National Park. Denver Service Center.

Tusayan Planning Committee

1994 Tusayan Area Plan. Tusayan, AZ.

Operations Research Consulting Associates

1993 "Grand Canyon North Rim Visitor Utilization Study." Prepared for the National Park Service. On file at Grand Canyon National Park, AZ.

U. S. Forest Service, U. S. Department of Agriculture

1987 Kaibab National Forest Plan. Williams, AZ.

1988 Public Comments and Forest Service Response to the DEIS, Kaibab National Forest Plan. Williams, AZ.

1990 Kaibab National Forest Plan Amendment. Williams, AZ.

Walt Disney World, Planning and Industrial Engineering

1992 "Grand Canyon South Rim Visitor Utilization Study." Prepared for the National Park Service. On file at Grand Canyon National Park, AZ. 


\section{Planning Team}

\section{- Denver Service Center}

Ann Moss, Team Captain/Landscape Architect

(plan start-August 1994)

Larry Norris, Team Captain/Outdoor Recreation Planner (October 1994-plan completion)

Karen Arey, Landscape Architect

Judy Dersch, Visual Information Specialist

Rick Ernenwein, Natural Resources Specialist

Randy Fong, Architect

Elmer Hernandez, Transportation A\&E Manager

Joan Huff, Visual Information Technician

Jere Krakow, Historian

Kevin Percival, Landscape Architect

Linda Ray, Visual Information Specialist

Greg Sorensen, Editor

Catherine H. Spude, Archeologist

Harlan Unrau, Historian

Shelley Wells, Civil Engineer

\section{- Grand Canyon National Park}

Jack Davis, Superintendent (plan start-1991)

Robert S. Chandler, Superintendent (1991-93)

Boyd Evison, Acting Superintendent (1993-94)

Robert L. Arnberger, Superintendent (1994-plan completion)

John Reed, Assistant Superintendent (plan start-1993)

Gary Cummins, Deputy Superintendent (1993-plan completion)

Brad Traver, Chief, Division of Professional Services

Jim Tuck, Park Ranger

Gigi Wright, Outdoor Recreation Planner

- Harpers Ferry Center

Paul Lee, Interpretive Planner

- Washington Office

Dave Sharrow, Water Resources

- Western Regional Office

Ray Murray, Chief of Planning, Grants and Environmental Quality 


\section{CONSULTANTS}

- Denver Service Center

Doug Cornell, Architect/Planner, retired

Pat Fleming, Chief, Civil Engineering Section, Western Team

Gary Johnson, Chief, Landscape Architecture Section, Western Team

Mike Morelli, Landscape Architect

Judy Rozelle, Concessions Specialist

Mike Spratt, Chief, General Planning Section, Western Team

John Philip Thys, Visual Information Specialist

Frank Williss, Compliance Specialist

- Grand Canyon National Park

Janet Balsom, Archeologist

Judy Bartzatt, North Rim District Ranger

Steve Bone, South Rim District Ranger

Doug Brown, Compliance Officer

Kim Crumbo, Resource Management Specialist

Curt Edlund, Chief of Maintenance and Engineering

Jerry Mitchell, Resource Management Specialist

Maureen Oltrogge, Public Affairs Office

Zehra Osman, Landscape Architect

Greer Price, Writer/Editor/Interpretive Specialist

Ellis Richard, Chief, Interpretation Division

Bruce Wadlington, Chief, Concessions Division

- Kaibab National Forest, U.S. Forest Service

Raymond Brown, District Ranger, North Kaibab Ranger District

George Gibbons, District Ranger, Tusayan Ranger District

- Washington Office

Jacob Hoogland, Chief, Environmental Quality Division

Paul Christensen, Water Resources

- Western Regional Office

Jim Huddleston, NEPA Coordinator, retired

Alan Schmierer, NEPA Coordinator

- Others

Doug Widmayer, Senior Traffic and Transportation Engineer, Peccia and Associates, Inc., Helena, MT 


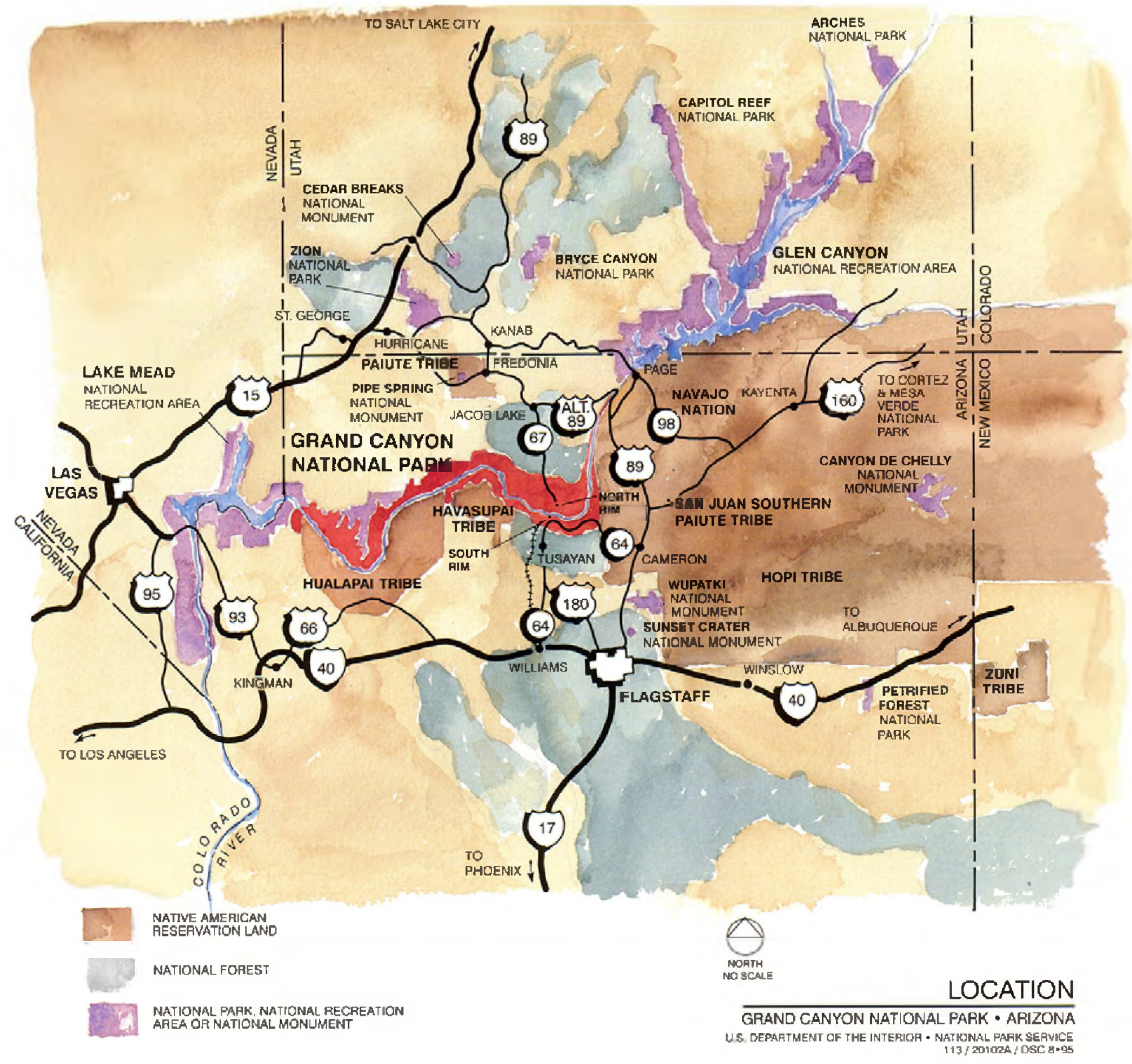




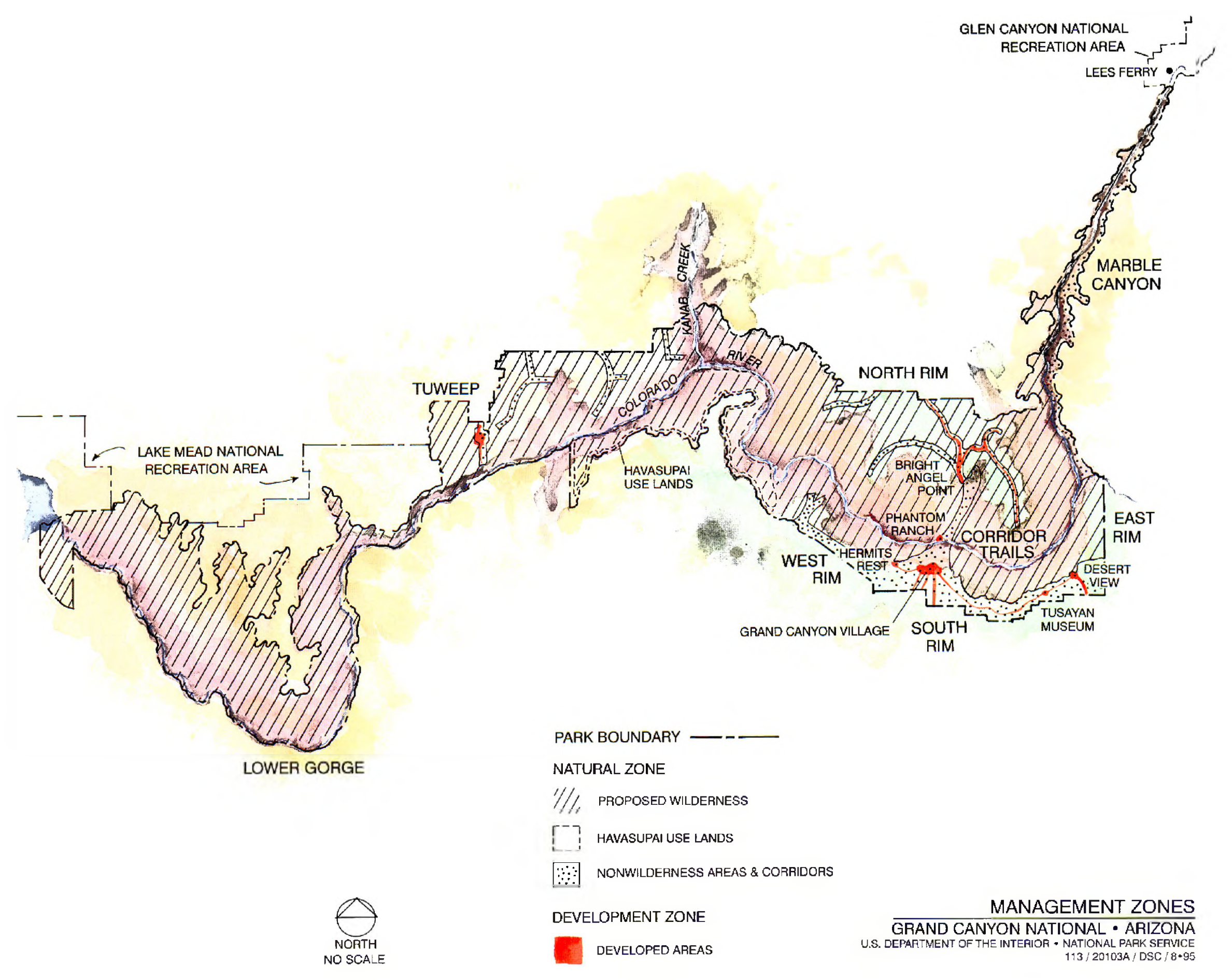



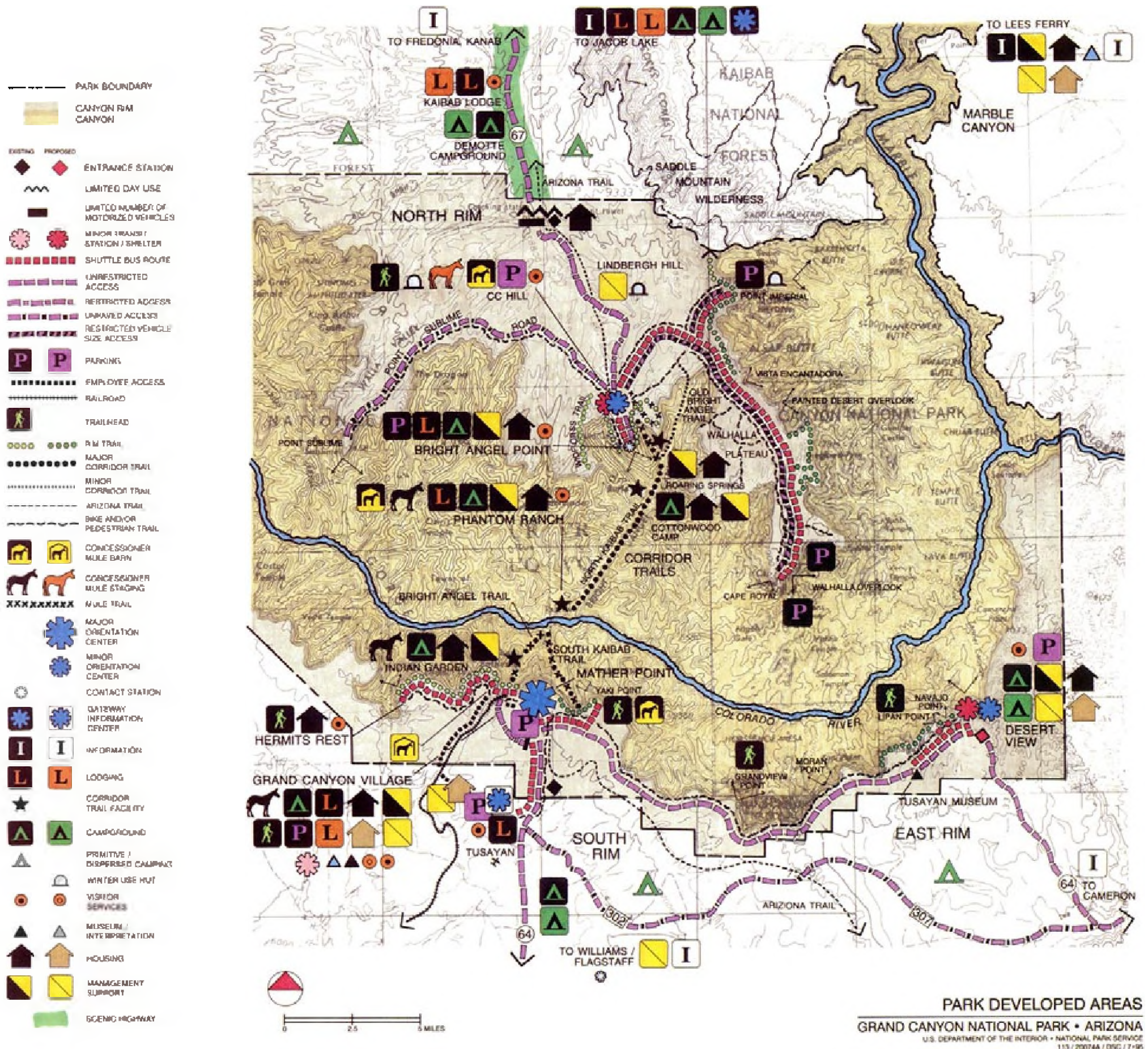


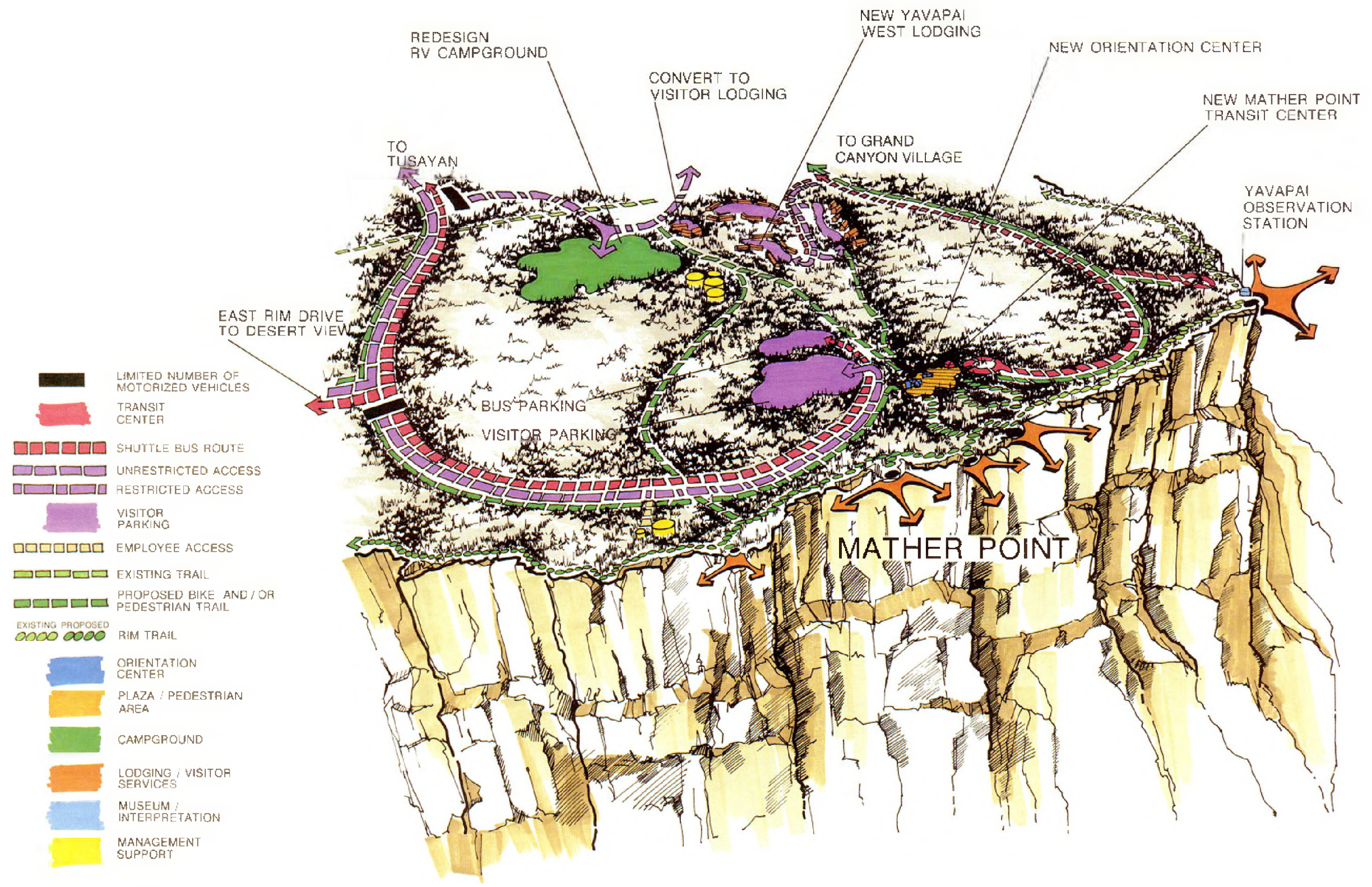

AERIAL VIEW MATHER POINT 


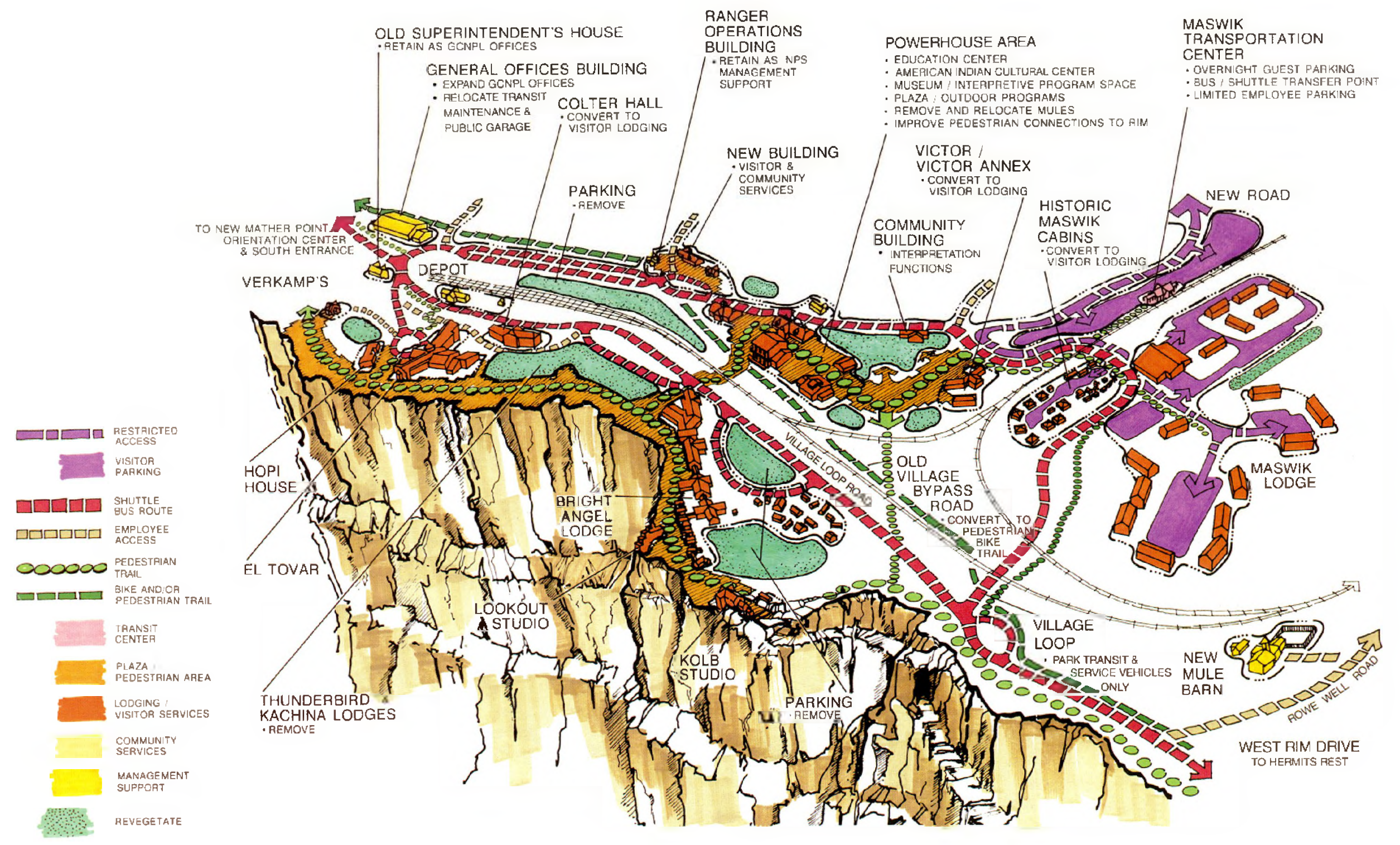




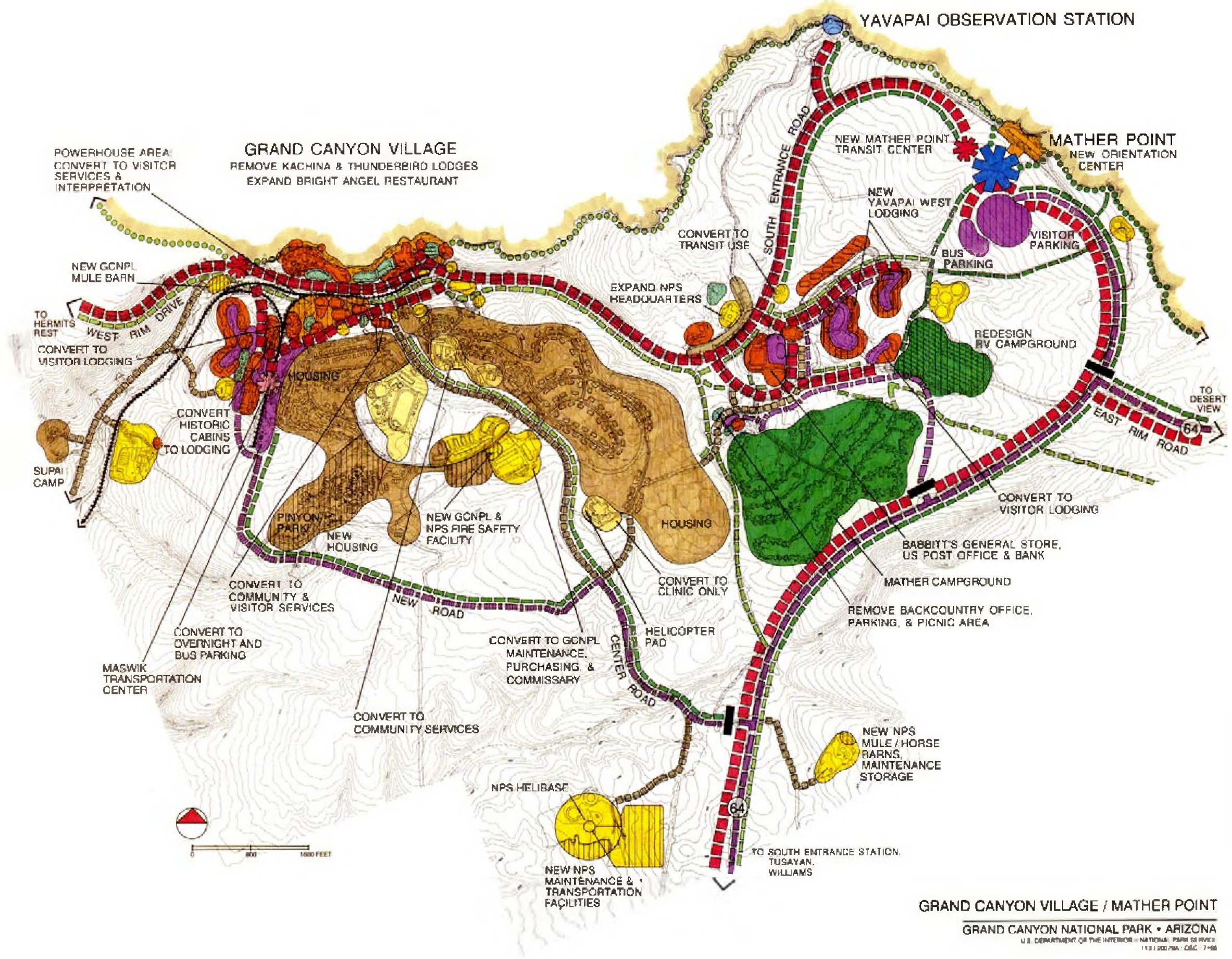




\section{GRAND CANYON VILLAGE}

Major changes will be made in visitor and employee use patterns in the village in order to minimize land disturbance and to accommodate large numbers of visitors without related conflicts or resource impacts.

Private vehicles will be removed from the rim and other high use areas, including the historic village. To ensure that visitors have convenient access to all park areas, public transit, bike, and pedestrian systems will be significantly expanded. Wherever possible, disturbed lands will be used for land use changes and development.

To enhance the village's historic character, parking areas and nonhistoric structures will be removed from the core area, private vehicles will be prohibited, and historic structures will be adaptively reused for visitor facilities and services.

To help visitors plan their visits and understand all the park's interpretive themes, a new orientation center will be provided near Mather Point, within walking distance of the rim. Parking for this facility will be accommodated nearby. 


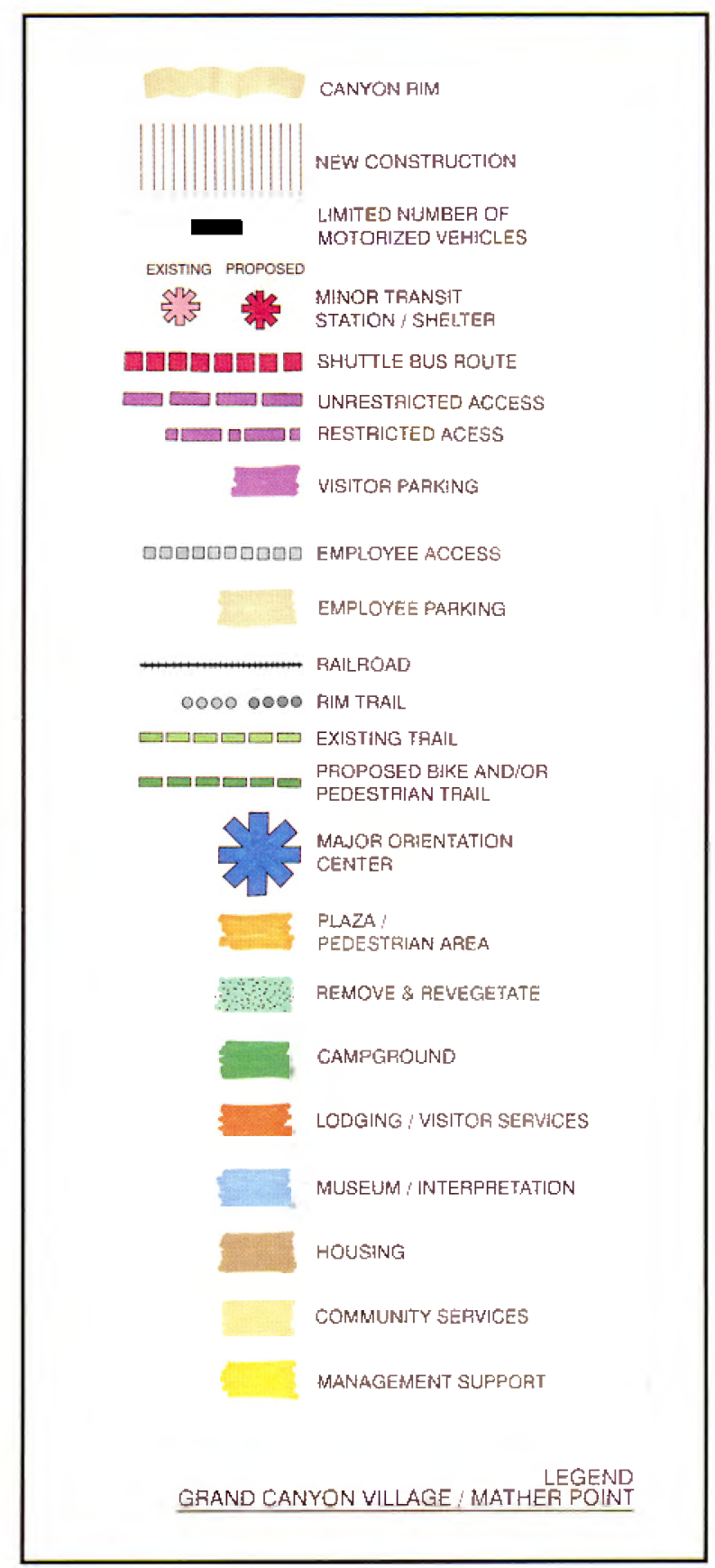




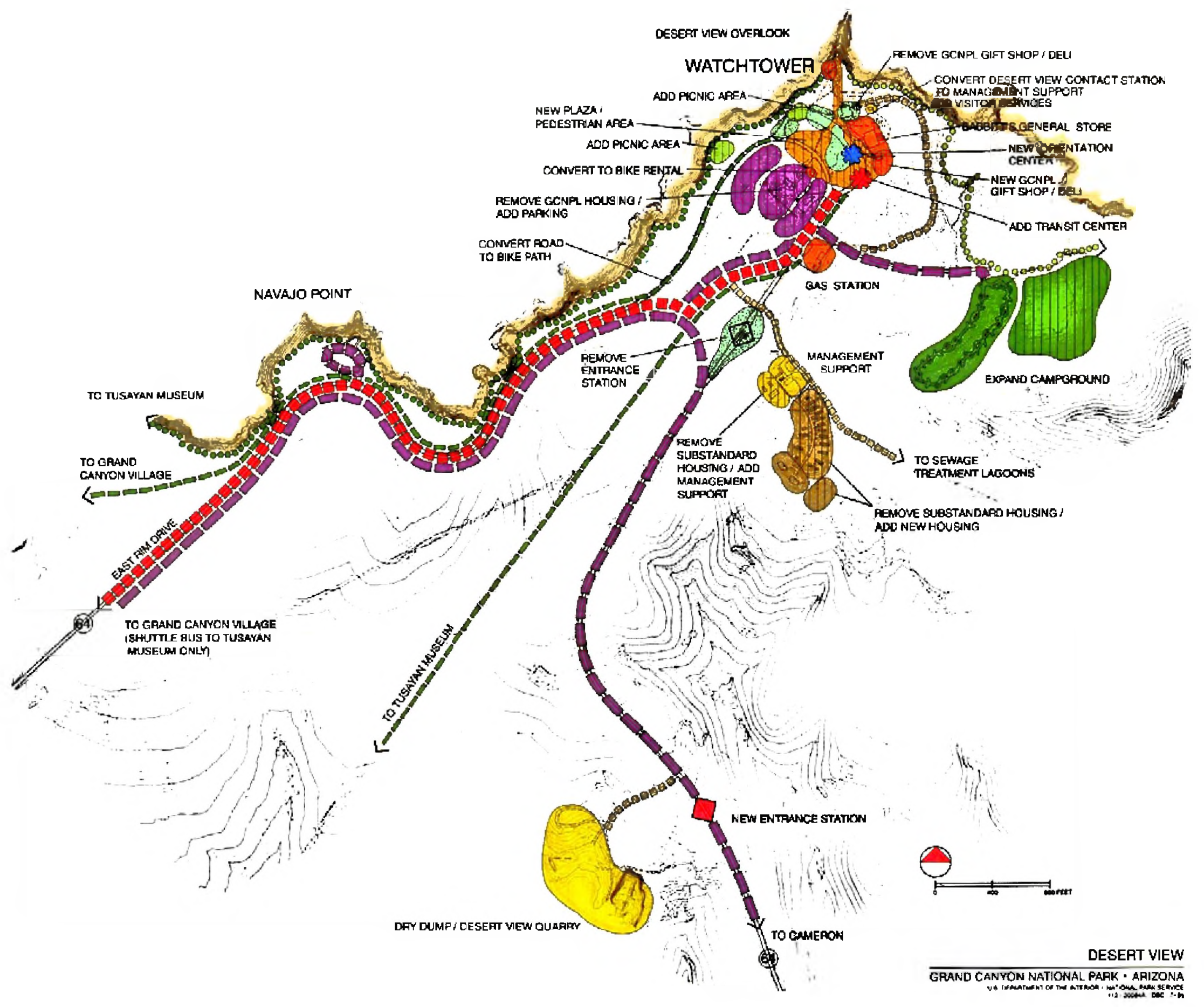




\section{DESERT VIEW}

Major changes will be made in visitor and employee use patterns at Desert View so as to minimize land disturbance and to accommodate large numbers of visitors without related conflicts or resource impacts.

East Rim Drive will be moved back from the rim so the Watchtower area can be used by visitors without intrusions from vehicles. Private vehicle parking and tour bus parking will be moved back from the rim to the existing concessioner housing area. Approximately 450 parking spaces will be provided.

Some visitor service buildings, including a new orientation center, will be built in disturbed areas within walking distance of the rim. 


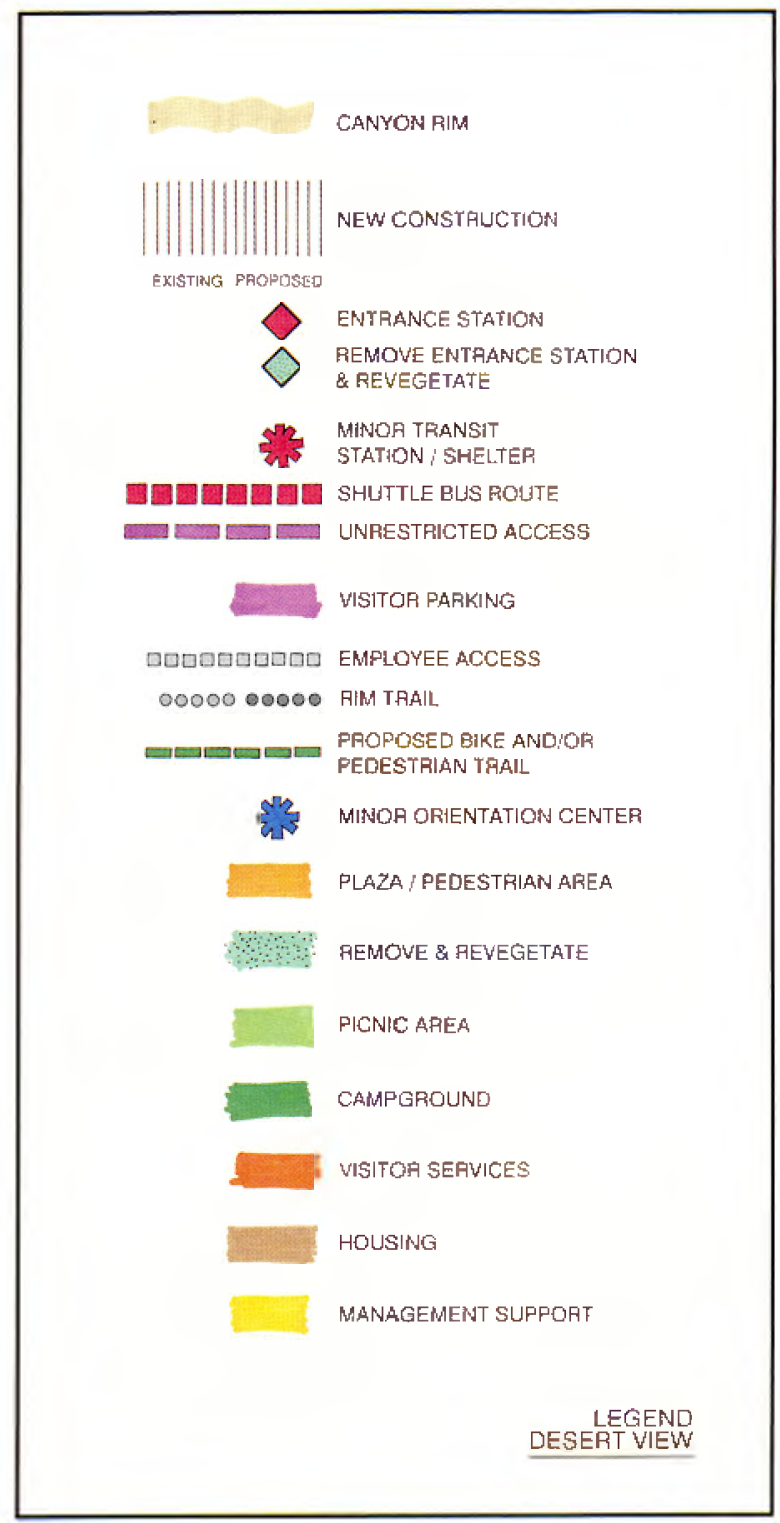



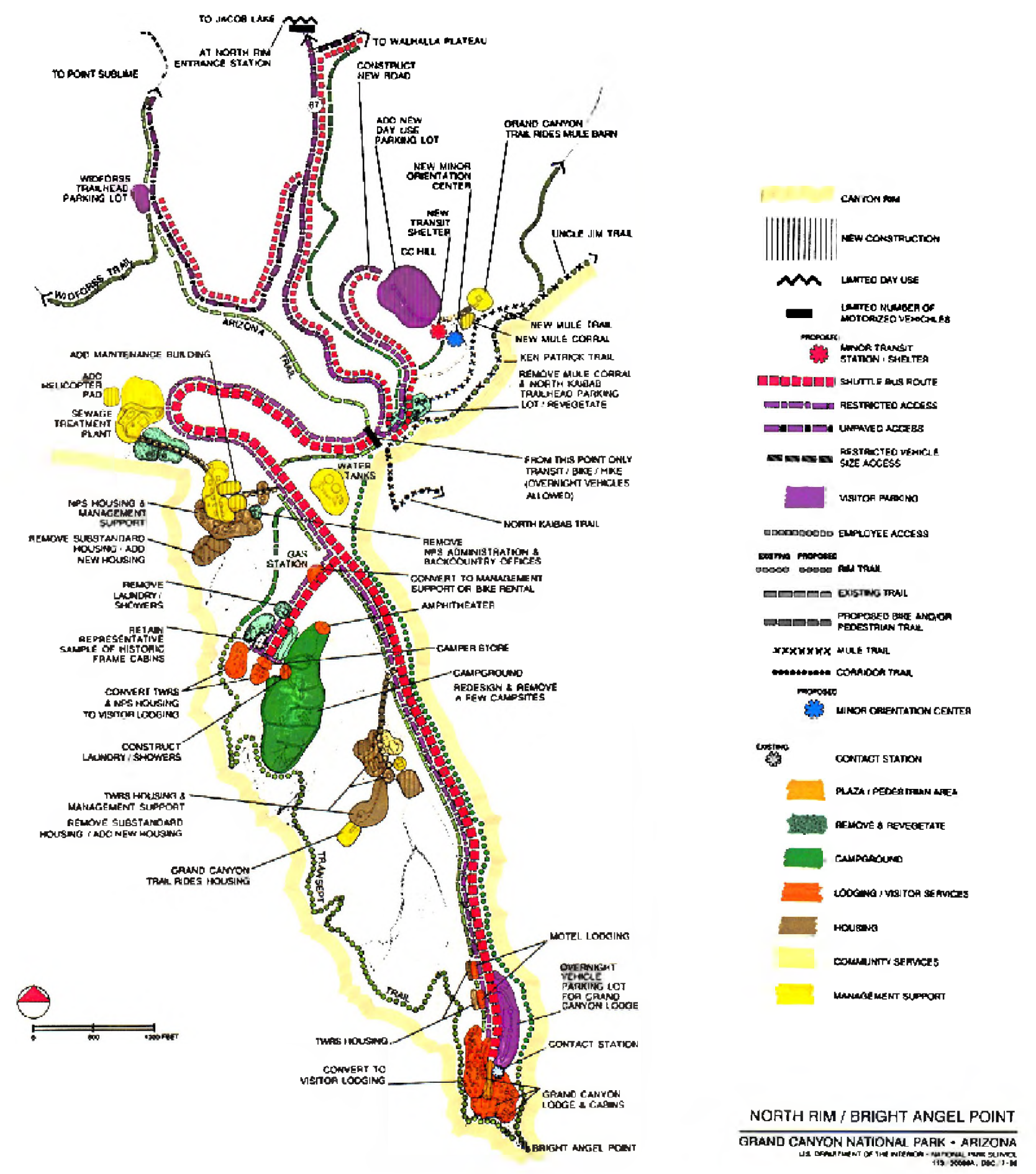


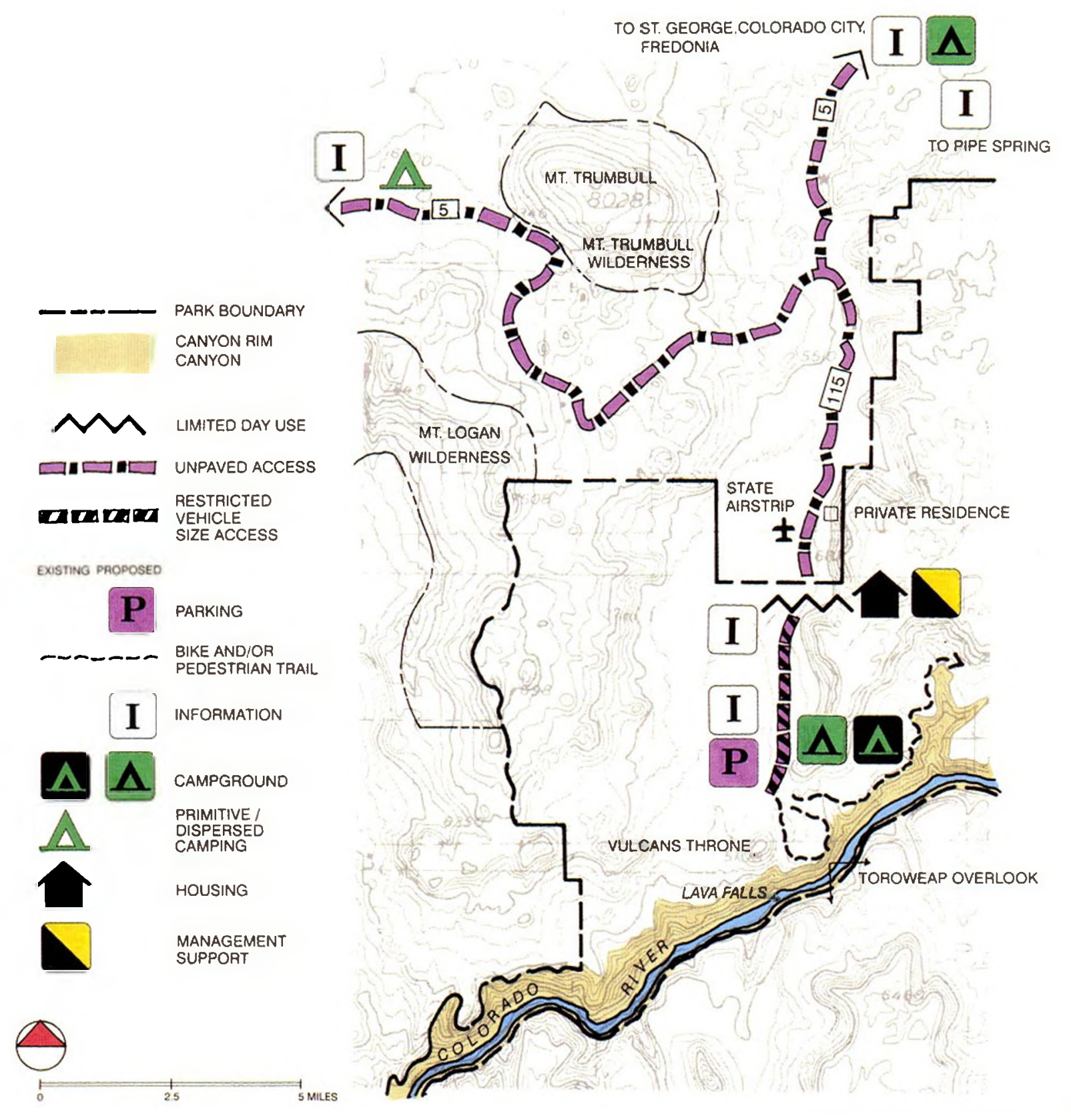

TUWEEP 